\title{
Antibacterial activity of iron oxide, iron nitride, and tobramycin conjugated nanoparticles against Pseudomonas aeruginosa biofilms
}

Leisha M. Armijo1', Stephen J. Wawrzyniec ${ }^{1}$, Michael Kopciuch', Yekaterina I. Brandt ${ }^{1}$, Antonio C. Rivera', Nathan J. Withers ${ }^{1}$, Nathaniel C. Cook', Dale L. Huber ${ }^{2}$, Todd C. Monson ${ }^{3}$, Hugh D. C. Smyth ${ }^{4}$ and Marek Osiński ${ }^{1 *}$ (1)

\begin{abstract}
Background: Novel methods are necessary to reduce morbidity and mortality of patients suffering from infections with Pseudomonas aeruginosa. Being the most common infectious species of the Pseudomonas genus, P. aeruginosa is the primary Gram-negative etiology responsible for nosocomial infections. Due to the ubiquity and high adaptability of this species, an effective universal treatment method for P. aeruginosa infection still eludes investigators, despite the extensive research in this area.

Results: We report bacterial inhibition by iron-oxide (nominally magnetite) nanoparticles (NPs) alone, having a mean hydrodynamic diameter of $\sim 16 \mathrm{~nm}$, as well as alginate-capped iron-oxide NPs. Alginate capping increased the average hydrodynamic diameter to $230 \mathrm{~nm}$. We also investigated alginate-capped iron-oxide NP-drug conjugates, with a practically unchanged hydrodynamic diameter of $\sim 232 \mathrm{~nm}$. Susceptibility and minimum inhibitory concentration (MIC) of the NPs, NP-tobramycin conjugates, and tobramycin alone were determined in the PAO1 bacterial colonies. Investigations into susceptibility using the disk diffusion method were done after 3 days of biofilm growth and after 60 days of growth. MIC of all compounds of interest was determined after 60-days of growth, to ensure thorough establishment of biofilm colonies.
\end{abstract}

Conclusions: Positive inhibition is reported for uncapped and alginate-capped iron-oxide NPs, and the corresponding MICs are presented. We report zero susceptibility to iron-oxide NPs capped with polyethylene glycol, suggesting that the capping agent plays a major role in enabling bactericidal ability in of the nanocomposite. Our findings suggest that the alginate-coated nanocomposites investigated in this study have the potential to overcome the bacterial biofilm barrier. Magnetic field application increases the action, likely via enhanced diffusion of the iron-oxide NPs and NP-drug conjugates through mucin and alginate barriers, which are characteristic of cystic-fibrosis respiratory infections. We demonstrate that iron-oxide NPs coated with alginate, as well as alginate-coated magnetite-tobramycin conjugates inhibit $P$. aeruginosa growth and biofilm formation in established colonies. We have also determined that susceptibility to tobramycin decreases for longer culture times. However, susceptibility to the iron-oxide NP

*Correspondence: osinski@chtm.unm.edu

${ }^{1}$ Center for High Technology Materials, University of New Mexico, 1313

Goddard Street SE, Albuquerque, NM 87106-4343, USA

Full list of author information is available at the end of the article

c) The Author(s) 2020. This article is licensed under a Creative Commons Attribution 4.0 International License, which permits use, sharing, adaptation, distribution and reproduction in any medium or format, as long as you give appropriate credit to the original author(s) and the source, provide a link to the Creative Commons licence, and indicate if changes were made. The images or other third party material in this article are included in the article's Creative Commons licence, unless indicated otherwise in a credit line to the material. If material is not included in the article's Creative Commons licence and your intended use is not permitted by statutory regulation or exceeds the permitted use, you will need to obtain permission directly from the copyright holder. To view a copy of this licence, visit http://creativeco mmons.org/licenses/by/4.0/. The Creative Commons Public Domain Dedication waiver (http://creativecommons.org/publicdomain/ zero/1.0/) applies to the data made available in this article, unless otherwise stated in a credit line to the data. 
compounds did not demonstrate any comparable decrease with increasing culture time. These findings imply that iron-oxide NPs are promising lower-cost alternatives to silver NPs in antibacterial coatings, solutions, and drugs, as well as other applications in which microbial abolition or infestation prevention is sought.

Keywords: Antibiotic resistance, Pseudomonas aeruginosa, Cystic fibrosis, Biofilm, Antibacterial agents, Drug delivery, Iron-oxide nanoparticles, Zero-valent iron nanoparticles, Magnetite, Alginate

\section{Background}

The discovery of antibiotics in 1928 was undoubtedly one of the most important developments in medicine to date, responsible for saving millions of lives by making formerly deadly infections curable [1]. Antibiotic reliability is the foundation for modern medicine and has facilitated the development of numerous, formerly impossible, medical procedures. Virtually every aspect of what we call modern medicine: treatment of autoimmune diseases and allergies, therapeutic use of corticosteroids or other immunosuppressant drugs, chemo- and radiation therapy, any and all surgical procedures, burn and wound treatment, to include any procedures or accommodations in which stents, catheters, orthodontic wires, ventilators, staples, sutures, bandages, clamps, belts, implants, or virtually any procedure in which an inert object-biological interface exists; they all put the patient at risk for infection. The development of antibiotic drugs made all this possible. On the other hand, researchers and medical professionals alike continue to struggle with the intensifying issue of antibiotic resistance, especially prominent in healthcare environments, which threatens to collapse the crucial foundation on which modern medicine was built.

Pseudomonas aeruginosa is one of the notorious ESKAPE pathogens (a group consisting of Enterococcus faecium, Staphylococcus aureus, Klebsiella pneumoniae,

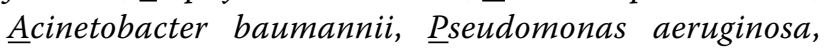
and Enterobacter species), which have developed resistance to the bulk of our current antimicrobial regimes, and instead "escape" the lethal action of antibiotics [2]. More specifically, many highly resistant Gram-negative bacteria from the ESKAPE group, including $P$. aerugi$n o s a$, are emerging as exceptionally noteworthy pathogens in threatening public health in United States as well as other parts of the world [3]. The ESKAPE bacteria are of tremendous concern because they are responsible for causing the overwhelming majority of nosocomial infections. Several reports identify significant limitations in current treatment options for these pathogens that force medical professionals to settle on the use of previously discontinued drugs having documented toxicity and unclear dosage and administration guidelines [4-8]. They also provide complex models of pathogenesis, transmission, and drug resistance $[2,3]$. Treatment regimens found to exhibit success against the ESKAPE bacteria can be applied to virtually any other species. Successful treatment of these species alone will result in significantly safer healthcare environments, more suitable for treating disease and illness.

Pseudomonas aeruginosa belongs to the Gram-negative Gammaproteobacteria class [9] and the Pseudomonadaceae family. Of all the species in the Pseudomonas genus, $P$. aeruginosa is the most common agent causing infections in humans [10]. It is abundant in the environment in general, and especially copious in the water and wastewater systems [10], making accidental inoculation difficult to avoid. P. aeruginosa infections are implicated in the morbidity and mortality of a wide spectrum of immunocompromised patients $[11,12]$. The seriousness of the problem with multiple-drug resistant $P$. aeruginosa has been highlighted in a recent WHO report, which placed it in the highest global priority "critical" category, together with A. baumannii and Enterobacteriaceae [13]. In the United States, an estimated 51,000 healthcareassociated $P$. aeruginosa infections are reported each year [14]. Of these, more than 6000 (13\%) are patients infected with multidrug-resistant strains, and approximately 400 deaths per year are attributed to these infections [14]. $P$. aeruginosa is not only one of the leading pathogens responsible for nosocomial infections [15-18], but also causes the morbidity and mortality of oncology and cystic fibrosis (CF) patients, where it is implicated in more than $90 \%$ of the occurrences of respiratory failure [19]. It is also prevalent in the burn units $[20,21]$, the intensive care units causing ventilator-associated infections [22, 23], and the neonatal intensive care units [24]. P. aeruginosa is the most prevalent isolate in intensive care units (ICUs), accounting for $23 \%$ of isolates, and the most common isolate taken from the human respiratory tract, accounting for $32 \%$ of isolates [25]. Ventilator-associated pneumonia (VAP) is a major cause of morbidity and mortality responsible for $25 \%$ of infections in ICUs [26, 27]. $P$. aeruginosa-related VAP results in high mortality, ranging from $40 \%$ to nearly $70 \%$ [28-31]. A recent report has also provided evidence that, of all the microbes causing bloodstream infections, $P$. aeruginosa is the one most commonly associated with mortality [32]. It possesses a significant number of virulence factors that work against 
the patient's immune system, making the bacteria highly adaptable and often lethal [33].

Production of a biofilm also contributes to the ability of $P$. aeruginosa to elude antibiotic treatments and host immune defenses; phagocytosis is frustrated, and antibody penetration is limited [34]. The phenotypic switch to the biofilm mode of growth is governed by gene modulation [35]. Van der Waals forces initially hold planktonic bacterial cells to a surface, where they can then use appendages such as flagella, cilia, or pili as an anchor for stronger adhesion [34]. It has been demonstrated that, during the attachment phase, the genes encoding synthesis of the extracellular matrix are activated $[34,36]$. The biofilm mode of growth is characterized, in general, by a reduced bacterial growth rate compared to the planktonic mode, the production of a protective extracellular polysaccharide (EPS) layer, and biofilm-specific gene activation [37]. The EPS layer constitutes a physical barrier, interfering with the ability of therapeutic antibiotic drugs to interact with the bacterial cells and exert their action. It is composed of several polymers as well as DNA; however, it consists primarily of alginate. Production of the alginate EPS by $P$. aeruginosa was initially discovered in 1966 by Linker and Jones [38]. Alginate is an anionic (negatively charged) co-block polymer composed of $\beta$-Dmannuronic acid (M) and C-5 epimer $\alpha$-L-guluronic acid (G) residues attached in a linear fashion by $1-4$ linkages [36, 39-42].

Biofilm infections are caused by multiple microbial species and, in general, are especially discommoding since they facilitate a means by which microbes are able to not only colonize a host tissue, but also inert objects such as surgical sutures, where they often cause chronic surgical site infections [43-45], orthodontic wires [46, 47], urinary or urethral catheters [48-50], venous or vascular catheters $[51,52]$, ureteral stents $[53,54]$, frontal recess stents [55], biliary stents [56] and respiratory (endotracheal) tubes $[57,58]$, among others. Biofilms also escalate the severity of infections in the respiratory tract, burns, and other open wounds, as well as virtually any other organ system [59]. The reduced efficacy of therapeutics caused by the presence of biofilm EPS layer serving as a barrier to antibiotic drug penetration limits treatment options even for antibiotic-susceptible strains [60]. In the case of treatment of biofilm infections in the CF respiratory tract, two barriers to drug diffusion exist: the biofilm EPS layer and the thick CF mucus layer (Fig. 1).

Significant research on silver NPs as antimicrobial agents has been reported in the literature [61-87] and much research has also been done on the efficacy of silver NPs against $P$. aeruginosa [88-99]. Due to their undisputable antibacterial properties, silver NPs are among the most commonly exploited nanomaterials in

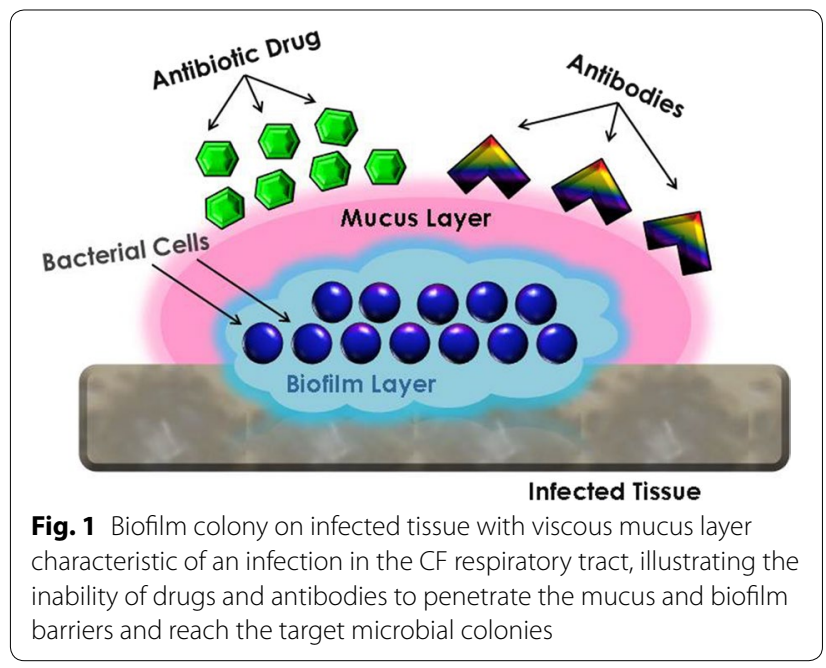

commercialized products [100]. Although silver NPs have demonstrated antimicrobial properties against many bacterial species, silver is costly, and is also known to exhibit toxicity in multiple species [101-103], including in vitro cytotoxicity in various human cell lines $[100,104,105]$. Most researchers attribute the observed toxicity either to silver ions [101] or the combination of silver NPs and silver ions $[103,104]$. An ideal bactericidal agent should be lethal to bacteria, but safe to human cells. One such candidate is iron and its compounds. Iron-oxide NPs have been shown to be non-toxic [106-109]. For example, feraheme/ferumoxytol containing superparamagnetic iron-oxide NPs was approved by the U.S. Food and Drug Administration as an iron supplement for treatment of iron deficiency in patients with renal failure [110-112]. According to a previous report, iron-oxide in NP form is not only non-toxic, but its byproduct, degraded iron from the cores, apparently accumulates in natural iron stores in the body [113]. Properly biofunctionalized ironoxide NPs have been shown to inhibit growth of Staphylococcus aureus [114-116] and Escherichia coli [115, 117], prevent biofilm formation by $P$. aeruginosa [118] and Streptococcus mutans [119], and exhibit bactericidal activity against a range of Gram-negative and Grampositive bacterial species [120-125]. While these are very encouraging results, more work is necessary in the investigation of iron-oxide NPs as a feasible alternative to silver NPs in the treatment of bacterial infections and for biofilm disruption.

It has also been established that the bactericidal activity of $\mathrm{Fe}_{3} \mathrm{O}_{4}$ NPs strongly depends on the surface coating and should be individually optimized for maximum effect on each bacterial species of interest [115, 124]. For example, changing the zeta potential of as-synthesized iron-oxide NPs from negative to positive by coating their surface 
with biocompatible chitosan has significantly increased their antimicrobial activity against Gram-positive Bacillus subtilis and Gram-negative Escherichia coli, reducing the percentage of viable cells after 22-h exposure to $50 \mu \mathrm{M}$ of NP suspension in nutrient broth from over $60 \%$ to less than $30 \%$ for either bacterial species [124]. Significant documented evidence suggests that the properties of the surface coating may account for the large differences in sensitivity results reported by various groups investigating the antibacterial effects of iron oxide, as the NPs used in the experiments often have different coatings. More research is necessary to thoroughly characterize the effects of surface coating on antibacterial properties.

In this paper, we report on the synthesis and characterization of iron-oxide (nominally magnetite) NPs capped with alginate and investigate the susceptibility of $P$. aeruginosa PAO1 bacterial colonies to iron-oxide NPs alone, as compared to tobramycin-conjugated iron-oxide NPs. Because uncapped iron-oxide NPs are unstable and aggregate at physiological $\mathrm{pH}$ of 7.4, they must be coated with a biocompatible polymer [126-128]. The coating must also contain additional, unbound functional groups for conjugation to a drug. For this study, we have opted to cap the NPs with natural alginate, rather than a synthetic polymer, to maintain green methodology and natural reagents. In addition, we anticipated that, since the bacterial biofilm is mostly composed of alginate, which is negatively-charged [129], the alginate-coating will impart a negative charge on iron-oxide NPs. It is well established that capping can be used to alter the surface charge of the iron-oxide NPs [125-128]. In our case, giving the nanocomposites similar negatively charged electrostatic properties to the target environment should promote diffusion through the alginate biofilms.

Iron-oxide (nominally magnetite) NPs with spherical morphology and a mean radius of $\sim 16 \mathrm{~nm}$ were used for this study. The NPs were synthesized using a solvothermal method on a Schlenk line under inert gas flow. After synthesis, the NPs were capped with natural alginate and half of the batch was crosslinked to tobramycin using 1-ethyl-3-(3-dimethylaminopropyl)carbodiimide hydrochloride (EDC, also abbreviated as EDAC or EDIC)/Nhydroxysulfosuccinimide (sulfo-NHS). Characterization was done using transmission electron microscopy (TEM), dynamic light scattering (DLS), X-ray diffraction (XRD), and energy-dispersive X-ray spectroscopy (EDS). Tobramycin-conjugated NPs, as well as unconjugated NP samples were used to determine the susceptibilities and minimum inhibitory concentrations (MICs) of established $P$. aeruginosa colonies. All the microbiological procedures were carried out in a Biosafety Level 2 laboratory. The susceptibility to zero-valent iron NPs was also investigated as a positive control. Tobramycin antibiotic was chosen for these studies because it has been shown to be the most active drug tested on clinical isolates of $P$. aeruginosa and has exhibited excellent activity against multidrug resistant (MDR) strains, usually in combination with other antibiotics [130-142].

\section{Methods}

\section{Synthesis and characterization of nanoparticles} and nanoparticle-drug conjugates

For the synthesis of iron-oxide (magnetite) NPs, we have adopted a two-step procedure of Park et al. [143], with subsequent modifications reported in [144]. Step one is the synthesis of the organic carrier, which delivers the metal atoms individually to the growing lattice. Step two is the high-temperature growth of the nanocrystalline particles. The organic carrier was the coordination complex iron oleate, (iron(II, III) [(9Z)-9-octadecenoate] $\mathrm{n})$, where $\mathrm{n}$ is the coordination number of iron. This molecule may form a monomer, dimer, or trimer [144, 145]. Iron oleate was produced in our laboratory using a procedure published in [144]. The iron oleate complex was synthesized in an ion-exchange reaction between sodium oleate salt (sodium (9Z)-9 octadecenoate) and iron(III) chloride hexahydrate $\left(\mathrm{FeCl}_{3} \cdot 6 \mathrm{H}_{2} \mathrm{O}\right)$. In this reaction, the sodium atom on the sodium oleate is replaced by iron, forming iron oleate, and the chloride and sodium ions combine to form sodium chloride. The iron oleate synthesis procedure was modified by adding an additional washing step. The product was washed with deionized (DI) water, ethanol, and acetone, to remove additional contaminants and purify the product prior to aging in the oven overnight. After the iron oleate was aged overnight in the oven, the NPs were synthesized from it, using a high molecular weight inert hydrocarbon as the solvent, and oleic acid as a stabilizing agent. In this method, the time separation between nucleation and growth events can be maximized to achieve better monodispersity as well as morphology control [144-146]. Zero-valent iron NPs were synthesized using the same procedure with the addition of sodium borohydride to reduce iron oxide to iron under inert gas flow. NPs were then capped with either alginate or succinylated polyethylene glycol (PEG) 5000. Aliquots of alginate-capped iron-oxide NPs were then crosslinked to tobramycin via EDC/sulfo-NHS.

\section{Materials}

Iron(III) chloride hexahydrate (97\%), sodium borohydride powder (98\%), m-PEG 5000 (methyl-terminated PEG) powder, sodium alginate from brown algae (A2158), succinic anhydride (>99\%), phosphate-buffered saline (PBS) powder, and TRIS hydrochloride (PharmaGrade) were purchased from Sigma-Aldrich; hydrochloric acid solution $0.02 \mathrm{~N}$ was purchased from Fisher 
Chemical; $n$-docosane (99\%) was purchased from Alfa Aesar; sodium oleate ( $>97 \%$ ) was purchased from Tokyo Chemical Industry Co.; hexanes (95\%), ethanol (99\%), acetone (99\%), chloroform (99.9\%), hexane (99\%), anhydrous pyridine $(99 \%)$, and methanol $(99 \%)$ were purchased from EMD Chemicals Inc.; EDC hydrochloride (cat\# 22981) and N-hydroxysulfosuccinimide (sulfoNHS) (cat \# 24510) were purchased from Thermo Fisher Scientific. All chemicals were used as received, without further purification.

\section{Synthesis of iron oleate precursor complex}

In a $1000-\mathrm{mL}$ three-neck flask with a condenser, using standard air-free conditions, $25.92 \mathrm{~g}$ of iron(III) chloride hexahydrate $\left(\mathrm{FeCl}_{3} \cdot 6 \mathrm{H}_{2} \mathrm{O}\right)$ and $87.60 \mathrm{~g}$ of sodium oleate were solvated by $96 \mathrm{~mL}$ of DI water, $192 \mathrm{~mL}$ of ethanol, and $336 \mathrm{~mL}$ of $99 \%$-hexane (to dissolve the organics). Under argon flow, the flask was heated to $70^{\circ} \mathrm{C}$ while stirring at $3000 \mathrm{rpm}$. The flask was kept refluxing at this temperature for $4 \mathrm{~h}$. Then, the product was washed 3 times with $96 \mathrm{~mL}$ of DI water (in 32-mL aliquots) using a separatory funnel. The mixture was then placed in a rotary evaporator (RotoVap) to evaporate away any remaining hexane. The flask was then vacuum sealed, and placed in the oven for $24 \mathrm{~h}$ at $70{ }^{\circ} \mathrm{C}$. The final product was a dark brown solid.

\section{Synthesis of iron-oxide (magnetite) NPs}

In a $500-\mathrm{mL}$ three-neck flask with a condenser, $16.20 \mathrm{~g}$ of the iron oleate complex produced above was combined with $2.57 \mathrm{~g}$ of oleic acid. $30 \mathrm{~mL}$ of either paraffin wax or docosane was added to the flask as a solvent, along with 5-10 boiling stones, since a characteristic nucleation event occurs at $200{ }^{\circ} \mathrm{C}$ and may cause the pressure to increase significantly. Under argon flow, the mixture was heated to $370{ }^{\circ} \mathrm{C}$ at a rate of $5{ }^{\circ} \mathrm{C}$ per minute and held at that temperature for $15 \mathrm{~min}$. After synthesis, the mixture was cooled to $50{ }^{\circ} \mathrm{C}$, and NPs were washed three times with 95\%-hexanes and acetone, and redispersed in chloroform. The iron-oxide NPs used in this study have a very narrow size distribution and the procedure produces consistent 16-17 $\pm 2 \mathrm{~nm}$ NPs per batch. The same batch of iron-oxide NPs characterized here was used as a precursor for the zero-valent iron NPs and iron nitride NPs, as well as in the biological studies.

\section{Synthesis of zero-valent iron NPs}

The NPs were synthesized in docosane in the same 500$\mathrm{mL}$ three-neck flask using the same method as above. However, the reactants were reduced with a molar equivalent of sodium borohydride $\left(\mathrm{NaBH}_{4}\right)$, as reported in the literature [147-151]. The reaction was carried out at $250{ }^{\circ} \mathrm{C}$ and kept at that temperature for $2 \mathrm{~h}$. The
NPs were separated from the docosane by diluting with a nonpolar solvent (95\%-hexanes) and using a permanent magnet for magnetic separation under air-free conditions (in an atmosphere-controlled glove box), Subsequently, the NPs were annealed under air-free conditions to remove any remaining organics prior to being capped with alginate as described below.

\section{Removal of oleic acid cap}

The iron-oxide NPs came out of synthesis capped with the oleate via a carboxyl group bound to the metal atoms, since iron oleate served as the organometallic (metal carbonyl) complex by which the iron was delivered to the iron-oxide crystal [144-146]. The oleate cap was removed with a hydrochloric acid wash.

The process of removing the cap is governed by the Henderson-Hasselbalch equation [152, 153], which derives the $\mathrm{pH}$ as a measure of acidity from $\mathrm{pK}_{\mathrm{a}}$ (the negative $\log$ of the dissociation constant) and the ratio of the concentrations of an undissociated acid and its conjugate base [154]:

$$
p H=p K_{a}+\log _{10}\left(\frac{[A-]}{[H A]}\right)
$$

where $\left[A^{-}\right]$is the conjugate base (oleate anion) concentration, and $[H A]$ is the organic acid (oleic acid in our case) concentration.

The $\mathrm{pK}_{\mathrm{a}}$ is given by [155]:

$$
p K_{a}=-\log _{10}\left(\frac{\left[\mathrm{H}_{3} \mathrm{O}^{+}\right]\left[\mathrm{A}^{-}\right]}{[H A]}\right)
$$

where $\left[\mathrm{H}_{3} \mathrm{O}^{+}\right]$is the hydronium ion concentration.

When the $\mathrm{pH}$ is equal to the $\mathrm{pK}_{\mathrm{a}}$, there will exist, in solution, an equal amount of protonated (acid) and deprotonated (conjugate base) molecules ([ $\left.\mathrm{A}^{-}\right] /$ $[\mathrm{HA}]=1$. A typical carboxylic acid has a $\mathrm{pK}_{\mathrm{a}}$ between 4 and 5 [154], however, titration experiments have shown that oleic acid has a much higher $\mathrm{pK}_{\mathrm{a}}$ of 9.85 [155]. An organic acid will be significantly deprotonated in a solution if its $\mathrm{pK}_{\mathrm{a}}$ is two or more units lower than the $\mathrm{pH}$ of the solution. Although the reaction would have proceeded at a higher $\mathrm{pH}$, we used an $\mathrm{HCl}$ solution having a $\mathrm{pH}$ of 1 to ensure a more rapid protonation and thus, detachment of oleate from the iron-oxide NP at $25{ }^{\circ} \mathrm{C}$. Inserting our $\mathrm{pH}$ value of 1 and the oleate $\mathrm{pK}_{\mathrm{a}}$ of 9.85 into Eq. 1 returns a value of 6974.3 for the ratio [HA]/ $\left[\mathrm{A}^{-}\right]$. Upon reaching this $\mathrm{pH}$, the yellow-tinged transparent oleic acid could be visually observed to fall out of solution. The NPs were separated in a 95\% hexanes/ methanol mixture, in which the methanol solvated the oleic acid. 


\section{Alginate capping}

Sodium alginate from brown algae is produced by the species Macrocystis pyrifera and consists of mannuronic and guluronic acids with an $\mathrm{M} / \mathrm{G}$ ratio of approximately $3 / 2$ and an average molecular weight of $46 \mathrm{kDa}$. Once the NP samples were uncapped and washed, sodium alginate was added to the NPs in a 1 to 3 alginate to NP ratio (by mass) in chloroform solvent. The mixture was sonicated at $40 \mathrm{kHz}$ for $4 \mathrm{~h}$ to ensure complete coverage. The alginate-capped NPs were washed three times in chloroform using centrifugation and dried in air. The alginate-capped NP could be stored long-term in powder form or reconstituted in water for immediate use. This capping procedure is the same for zero-valent iron and iron-oxide NPs.

\section{Polyethylene glycol succinylation and capping}

Alternatively, instead of alginate, iron-oxide NPs were capped with a non-biodegradable polymer, succinylated PEG. To enhance the binding affinity of PEG-OH to the NPs, we further engineered $\mathrm{mPEG}$ using a simple succinylation procedure. mPEG-5000 was chosen, as it is an FDA-approved polymer and its use in biomedical applications has been well-documented [156-163]. Succinylated PEG was produced in-house from the PEG-OH terminal of $\mathrm{mPEG}$ in a process, during which the terminal hydroxyl group was converted, by a small chain extension, to a more electronegative carboxyl group. This enhances binding affinity, and thus promotes long-term colloidal stability even under increasing salinities.

For the reaction, five grams of 5000 molecular weight mPEG powder were added to a three-neck flask, purged with nitrogen, and placed on a stirring/heating mantle with a magnetic stir bar. Septa were placed on the other two flask necks, with a nitrogen adaptor on the central neck to purge with nitrogen. To keep a sealed pyridine bottle under close to atmospheric pressure, $25 \mathrm{~mL}$ of nitrogen gas were drawn up into a syringe through the septum of a nitrogen-filled three-neck flask connected to the Schlenk line and injected into the pyridine bottle. After injection, $25 \mathrm{~mL}$ of anhydrous pyridine were drawn up from the bottle and injected into the nitrogenfilled flask. The temperature controller was set to $50{ }^{\circ} \mathrm{C}$, the temperature at which the solid mPEG dissolves. Subsequently, $2.5 \mathrm{~g}$ of succinic anhydride were added to the three-neck flask. This reaction process lasted for $1 \mathrm{~h}$ at $50{ }^{\circ} \mathrm{C}$. The addition of pyridine was repeated four more times using the same methodology as described above, and the reaction could continue for another $2 \mathrm{~h}$ at $50{ }^{\circ} \mathrm{C}$. The pyridine solvent, which has a boiling point of $115.3{ }^{\circ} \mathrm{C}$ at $1 \mathrm{~atm}$, was removed using the rotary evaporator set at $40-50{ }^{\circ} \mathrm{C}$ to facilitate evaporation separation of the solvent. The evaporation procedure was followed by three DI water washes. The product was then re-dissolved in DI water and placed in 1-kDa-cutoff dialysis tubing in a 1 -L beaker filled with DI water. The succinylated 5-kDa PEG was trapped inside, while the lighter precursor materials could diffuse out of the bag into the surrounding fluid (dialyte). The DI water in the 1-L beaker was replaced after 2, 4, and $8 \mathrm{~h}$. Figure 2 shows the purification through dialysis with $1-\mathrm{kDa}$ dialysis bags. After dialysis purification, the mixture was dried with the rotary evaporator, with the water bath set to $50{ }^{\circ} \mathrm{C}$, the same as the synthesis temperature. The dried succinylated PEG was still liquid at this temperature and turned into a light-brown waxy solid when cooled to room temperature. After succinylation, PEG capping was performed using a modified procedure from [164]. For our work, we only used the succinylated PEG, prepared from $\mathrm{mPEG}$ as described above, as opposed to the costlier phospholipids with PEG tails used in [164].

The iron-oxide NPs were solvated in chloroform and combined with PEG using a NP-to-PEG mass ratio of 1:2. The NP/polymer solution was sonicated at $40 \mathrm{kHz}$ for an hour at room temperature. The NPs were then washed three times with DI water via centrifugation, before being resuspended in DI water.

\section{Conjugation to tobramycin}

Drug conjugation to tobramycin was done using EDC with sulfo-NHS. Sulfo-NHS is a chemical modification reagent used in the conversion of carboxyl groups to amine-reactive esters in bioconjugation or crosslinking. Sulfo-NHS is a charged analog of NHS (N-hydroxysuccinimide) and, like NHS, facilitates control and alteration of carbodiimide crosslinking reactions in which carboxylates $(-\mathrm{COOH})$, such as those present in the polymer molecule, are activated for conjugation with primary amines $\left(-\mathrm{NH}_{2}\right)$ found on the tobramycin molecule. Such derivatives are synthesized by mixing the sulfo-NHS with

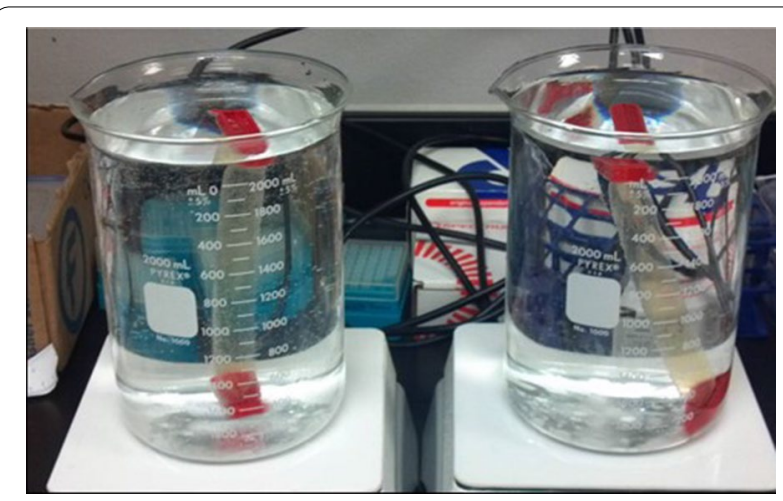

Fig. 2 Purification of succinylated polyethylene glycol (PEG) through dialysis tubing in deionized (DI) water 
a carboxyl-containing molecule, such as alginate, citrate, or carboxy-PEG, with a dehydrating agent such as the carbodiimide EDC. EDC is a "zero-length cross-linker", meaning that it acts by bringing the two molecules of interest together, but does not change their combined size by increasing the polymer chain length. In the first step of the reaction, the carboxylated particles are activated by addition of the EDC, followed by the formation of a reactive ester intermediate, O-acylisourea. After that, the ester will react with an amine group forming an amide. However, this amide is highly unstable and will hydrolyze, regenerating the carboxyl group, if it does not encounter another amine functional group. Our procedure was modified for our purposes from a generic procedure for EDC crosslinking of carboxyl and amine terminal functional groups [165]. To conjugate the NPs capped with any of the above-mentioned organic molecules or polymers, $100 \mathrm{mg}$ of $\mathrm{Fe}_{3} \mathrm{O}_{4}$ NPs washed three times with $10 \mathrm{~mL}$ of coupling buffer $(50 \mathrm{mM}$ phosphate buffered saline, $\mathrm{pH}$ 7.2) were removed by magnetic separation. The purified NPs were then suspended in $5 \mathrm{~mL}$ of coupling buffer. To ensure an excess of the ligand, $50 \mathrm{mg}$ of tobramycin ( $50 \mathrm{mg}$ of tobramycin per $100 \mathrm{mg}$ of NPs) were dissolved in coupling buffer, thus making a $10 \mathrm{mg} /$ $\mathrm{mL}$ tobramycin solution. Under gentle stirring, the NP solution was added drop-wise into a beaker containing the tobramycin solution, and allowed to sit for $2 \mathrm{~min}$ at $450 \mathrm{rpm} .100 \mathrm{mg}$ of EDC for each $100 \mathrm{mg}$ of NPs were added to the reaction mixture, under stirring until solvated. Then, $5 \mathrm{mM}$ sulfo-NHS was also added to the reaction vessel. The conjugation reaction could proceed for $4 \mathrm{~h}$ at room temperature under gentle stirring. Afterwards, the NPs were washed twice with $5 \mathrm{~mL}$ of coupling buffer, before being resuspended in coupling buffer containing $35 \mathrm{mM}$ Tris to block excess reactive sites. Finally, the NPs were washed twice again, suspended in DI water, and stored in the refrigerator. Conjugation to tobramycin was confirmed with Fourier-transform infrared (FTIR) spectroscopy done on EDC-crosslinked NP-tobramycin nanocomposites in $\mathrm{KBr}$ pellets.

\section{Nanoparticle characterization \\ Structural and compositional characterization}

High-resolution TEM (HRTEM) measurements were taken with a JEOL-2010F transmission electron microscope operating at $200 \mathrm{kV}$ and equipped with an Oxford Instruments 200 EDS apparatus, fitted with an Inca X-Site Ultra-Thin Window EDS detector. TEM samples were prepared by placing a drop of the colloidal solution onto a 200-mesh carbon-coated copper grid, and the solvent was allowed to dry, fixing the nanocrystals on the grid. To obtain elemental composition using EDS, the electron beam was focused on a single nanocrystal and the peaks were identified using the Oxford Instruments ISIS software. Data obtained from multiple singlenanocrystal measurements showed good repeatability. X-ray diffraction (XRD) was performed on a Rigaku ${ }^{\circledR}$ Ultima III X-ray diffractometer. The colloidal sample was applied to a heated glass slide and the solvent was evaporated away, affixing the sample to the slide.

\section{Size determination}

Hydrodynamic size distributions of the nanocrystals have been measured using a DynaPro Titan DLS module from Wyatt Technology Corporation. In order to reduce aggregation and maximize the accuracy of the measurement, samples were prepared for analysis by diluting the NP@oleate stock solution to $50 \mu \mathrm{g} / \mathrm{mL}$ in pure chloroform. The NP@alginate stock solution was diluted in DI $\mathrm{H}_{2} \mathrm{O}$. The 1-mL samples were vortexed, then sonicated at $40 \mathrm{kHz}$ for $5 \mathrm{~min}$ prior to analysis to separate agglomerates and ensure that a more homogeneous solution was analyzed.

\section{Magnetic characterization}

Magnetic characterization was performed on oleatecoated NPs using a Quantum Design magnetic property measurement system (MPMS) superconducting quantum- interference device (SQUID) magnetometer. Magnetic hysteresis measurements were conducted at $293 \mathrm{~K}$. Temperature-dependent magnetic properties were measured at a range from 10 to $350 \mathrm{~K}$. To measure the zerofield cooling (ZFC) and field-cooling (FC) magnetization curves, three steps were carried out as follows: First, NP samples were gradually cooled in a zero magnetic field from room temperature to $5 \mathrm{~K}$. Then, a magnetic field of 100 Oe was applied to measure the ZFC magnetization curve in a warming process from 10 to $350 \mathrm{~K}$. Last, the FC curve was measured under the same applied field in a cooling process from 350 to $10 \mathrm{~K}$.

\section{Zeta potential measurements}

Zeta potential measurements have been used to characterize the electrostatic potential at the electrical double layer that forms at the interface of a colloidal NP and the dispersing solvent. Although the zeta potential measurement is often regarded as NP surface charge, it is not actually a measure of surface charge. Zeta potential measures the potential difference between the dispersion medium and the adsorbed layer of solvent ions surrounding the particle. This is not equal to the surface charge or the Stern potential [166], which are defined at a different location. Colloids with a zeta potential between -10 and $+10 \mathrm{mV}$ are considered neutral, while colloids with a zeta potential greater than $30 \mathrm{mV}$ or smaller than $-30 \mathrm{mV}$ are considered strongly cationic, or anionic, respectively 
[167]. Particles with a large measured value of zeta potential, whether negative or positive, are electrostatically stabilized, whereas particles with low absolute values of zeta potential aggregate or flocculate [167-169]. According to Liao et al. [170], iron-oxide NPs in water had a zeta potential of $+16.1 \mathrm{mV}$ (incipient stability), which shifted to $-60.1 \mathrm{mV}$ (good-excellent stability) after capping with alginate. Because most cell membranes are negatively charged, zeta potential is a key parameter in membrane permeability, and cationic particles tend to exhibit toxicity associated with membrane disruption (lysis) [167]. In our case, the alginate coating will impart the nanocomposites similar negatively charged electrostatic properties to the target membrane and biofilm environment, which should promote diffusion through the alginate biofilms, while also imparting the colloid significant stability at physiological $\mathrm{pH}$.

\section{Fourier transform infrared (FTIR) spectroscopy}

FTIR spectroscopy was performed on tobramycin-conjugated NPs to confirm the successful conjugation of the drug. Since neither the tobramycin molecule, nor the capping polymer have an amide linkage preexisting in their structure, the presence of an amide bond (1630$1681 \mathrm{~cm}^{-1}$ ) can be used to verify a successful EDC conjugation. The samples were dispersed in $\mathrm{KBr}$ pellets for FTIR analysis.

\section{Microbiological methods}

P. aeruginosa cultures in $75 \%$ glycerol were preserved frozen in a liquid nitrogen tank. The broth medium was inoculated $\sim 48 \mathrm{~h}$ prior to the start of the study. The liquid cultures were grown overnight on a rotary shaker at $37^{\circ} \mathrm{C}$ and $150 \mathrm{rpm}$. After that, the cultures were diluted to an optical density $(\mathrm{OD})$ at $600 \mathrm{~nm}\left(\mathrm{OD}_{600}\right)$ between 0.5 and 0.6. The cultures grown overnight in liquid media were tested for MIC of tobramycin, prior to being maintained as biofilm colonies. $\mathrm{OD}_{600}$ is a well-established method to determine bacterial cell concentration (in $\mathrm{mg} / \mathrm{mL}$ ) from the linear determination of colony forming units (CFUs), or viable cells capable of replication under the controlled conditions, in the media [171]. The number of CFUs corresponding to the optical density for $P$. aeruginosa at an $\mathrm{OD}_{600}=1.0$ is $2.04 \times 10^{8} \mathrm{CFU} / \mathrm{mL}$, which is equal to a bacterial concentration of $2.085 \mathrm{mg} / \mathrm{mL}$ [171]. $\mathrm{OD}_{600}$ was determined using Cary 5000 UV-VIS-IR spectrophotometer against a blank cuvette. This concentration was then used for subsequent inoculation of cultures used in the study.

P. aeruginosa $\mathrm{PAO} 1$ biofilm communities were grown on sterile boiling stones in liquid growth media for 60 days until firmly established. We have chosen PAO1, a derivative of the original Australian PAO isolate, as it is the most commonly used strain for research on this ubiquitous and metabolically versatile opportunistic pathogen. It has been distributed worldwide to numerous laboratories and strain collections. All MIC and susceptibility experiments were done in triplicate and repeated, for a total $n$ of 6 . MIC of tobramycin was measured over time on day 1 after one overnight incubation (in liquid culture without boiling stones), day 3, day 10, and day 60 . Motility testing was done on cultures after 1-day, 3-days and 60-days of growth. Motility testing was done by preparing agar in test tubes and inoculating the agar using the stab technique with a sterile inoculation loop having a pointed end. In this method the sharp end of the inoculation loop is dipped into the cultures and stabbed into the agar inside of the test tube one time. The tubes are then incubated overnight and observed the next day. Motile strains can be seen to have disrupted the agar surrounding the place where the stab inoculation was inserted into the agar. This disruption of the agar is not detectable in non-motile strains.

Previous studies on $P$. aeruginosa biofilms reported using a growth period of 6 days [172, 173]. However, another group reported that after 7 days of biofilm formation the accumulation of biomass had not yet reached a plateau [174], while a classic publication reported that 5 weeks of growth was the optimal amount of time to achieve the maximum amount of biomass [175]. In yet another report, in which the mucoid phenotype observed in $P$. aeruginosa typical of CF infections was investigated, biofilm cultures were maintained for 90 days [176]. It has also been reported that 30 to 60-day-old biofilms are more resistant to some stresses [177]. Therefore, although much of research on P. aeruginosa is reported on biofilms which have undergone shorter term growth, it appears that short term cultures are only merited for in vitro diagnostics, as they were originally intended. In diagnostic studies, colonies are allowed to differentiate just long enough to obtain diagnostic and sensitivity information. Longer term studies, although costlier, are no doubt merited in research settings due to the documented difference and robustness of established colonies. Since we are interested in modeling a typical $P$. aeruginosa infection in CF patients which is an established infection, known to have more inherent resistance to antibacterial agents, we maintained our biofilms for a period of 60-days prior to testing susceptibility to NPs and NP-tobramycin conjugates. The established biofilm colonies produced a thick EPS matrix and several pigments characteristic of P. aeruginosa biofilms: pyocyanin (blue-green) (Fig. 3), pyoverdine (fluorescent yellow-green), and pyorubin (red-brown). The optical color changes were noted and crystal violet staining was done to verify the presence of biofilms. 


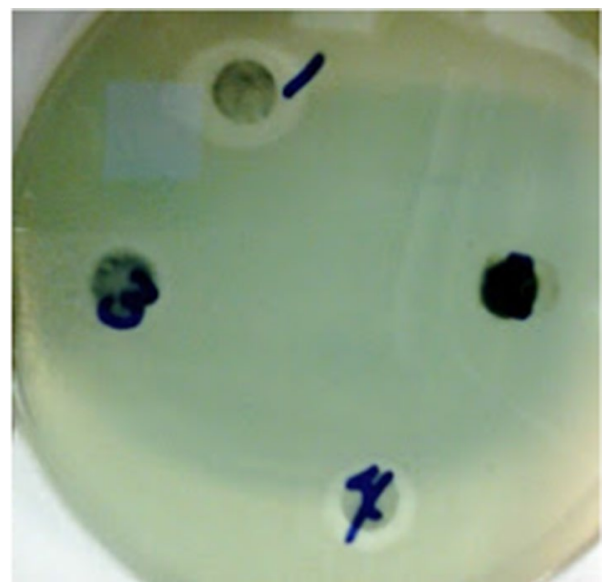

Fig. 3 Image showing the presence of pyocyanin (blue-green) pigment produced by $P$. aeruginosa cultures grown on agar plates

Luria Bertani (LB) broth (cat \#11006-004) and LB agar (cat \#11006-001) were purchased from IPM Scientific, Inc. Eldersburg, Maryland, USA. Crystal violet staining was used to determine the amount of incubation time needed for biofilm formation. $100-\mu \mathrm{L}$ dilutions of the P. aeruginosa (ATCC 27853) cultures were incubated overnight at $37{ }^{\circ} \mathrm{C}$ in $\mathrm{LB}$ broth in microtubes, without the addition of biofilm-promoting medium. Then, the liquid medium was decanted, and the tubes were gently rinsed with DI water. A $0.1 \%$ solution of crystal violet was prepared and $\sim 100 \mu \mathrm{L}$ of the solution was added to the microtube and incubated for $20 \mathrm{~min}$ before being rinsed $3 \times$ with DI water. The presence of the biofilm appears as a "ring" in the tube, at the interface of the growth medium and air. After $48 \mathrm{~h}$ of growth biofilms were apparent, as mucoid colonies adhered heavily to the cap and were visible, having a sticky, "egg white" consistency, stretching from the cap to the vial whenever the cap was removed.

$P$. aeruginosa cultures were grown in LB broth on sterile boiling stones at $37{ }^{\circ} \mathrm{C}$ for 60 days. The liquid medium was decanted every $24-48 \mathrm{~h}$, leaving only attached cells in the culture. The cells were then replenished with fresh broth. This method is a lowcost alternative to a flow chamber. After the 60-day period, the cultures were sonicated for the removal of attached cells, and once again, diluted to an optical density at a $600 \mathrm{~nm}$ wavelength $\left(\mathrm{OD}_{600}\right)$ between 0.5 and 0.6. $\mathrm{OD}_{600}$ was determined using Cary $5000 \mathrm{UV}-$ VIS-IR spectrophotometer against a blank cuvette, which contained only uninoculated broth. Once diluted, the cultures were tested in liquid media or applied to agar plates for susceptibility testing.

\section{Antimicrobial susceptibility tests}

The disk diffusion method is one of the most popular approaches to bacterial sensitivity testing due to its low cost and efficiency. The disk, impregnated with a candidate antibiotic drug or compound of interest, was placed on the inoculated agar, which contained a uniform layer of bacteria taken from liquid culture. The disks are commercially available, containing the proper concentrations of antibiotic drugs recommended for susceptibility testing by the Clinical and Laboratory Standards Institute (CLSI), the institution responsible for maintaining standards for such research. The underside of the plate was numbered for each sample to be tested. Alternatively, disks containing different concentrations of the compound of interest can be prepared in the laboratory. The method used was the agar disk diffusion, as described by CLSI, with impregnated disks applied to the cultured agar plates overnight for 16-18 h [178].

Approximately $10^{8} \mathrm{CFU} / \mathrm{mL}$ of bacterial cultures, corresponding to $\sim 1 \mathrm{mg} / \mathrm{mL}$ concentration, as determined by OD measurements, was distributed evenly onto a sterile agar plate using a sterile cotton swab to form a uniform layer on the agar. The disks, impregnated with NPs, drug, or NP-drug conjugates were then placed on top of the agar. A previous method of impregnation, the dip method, in which dry disks were dipped into known concentrations by forceps and then placed onto the agar cultures was found to produce inconsistent results because it was shown that the disks can absorb different amounts of liquid, introducing variability in the absorbed concentrations [179]. Instead, the more accurate drop method described by Sabath [180] was used. In this method, the dry disks are placed on the agar plates, then a known volume. The dry disks were placed atop the cultures and a $0.1 \mu \mathrm{L}$ drop of the solution of interest at the desired concentration was applied to the disk using a micropipette calibrated micropipette. This method eliminates variability in the total absorbed amount since a known volume is applied. Disk concentrations of tobramycin were initiated at the CLSI recommended disk content for tobramycin, corresponding to $10 \mu \mathrm{g}$ absorbed into the disk, when this mass returned a negative susceptibility, the concentrations were increased incrementally, until a susceptible mass was determined. For the initial disk diffusion study investigating tobramycin, NPs, and NP-conjugates, the mass on the disk was determined from concentration and applied volume. For example, a $0.1 \mu \mathrm{L}$ aliquot of a solution having a concentration of $100 \mathrm{mg} / \mathrm{mL}$ corresponds to $10 \mu \mathrm{g}$ in the disk $\left(0.1 \mu \mathrm{L}^{*} 100 \mathrm{mg} / 1 \mathrm{~mL}=10 \mu \mathrm{g}\right)$, a $50 \mathrm{mg} / \mathrm{mL}$ concentration corresponds to $5 \mu \mathrm{g}$ in the disk $\left(0.1 \mu \mathrm{L}^{*} 100 \mathrm{mg} / 1 \mathrm{~mL}=5 \mu \mathrm{g}\right)$, and a $25 \mathrm{mg} / \mathrm{mL}$ concentration corresponds to $2.5 \mu \mathrm{g}$ in the disk $(0.1$ $\mu \mathrm{L}^{*} 25 \mathrm{mg} / 1 \mathrm{~mL}=2.5 \mu \mathrm{g}$ ), and so on. All doses based on 
concentration or weight correspond to the total nanocomposite, not to NPs, PEG, or tobramycin alone. The cultures were grown under the previous conditions overnight $(16-18 \mathrm{~h})$ at $37{ }^{\circ} \mathrm{C}$. The diameter of zone of inhibition around the disc was observed and recorded. A CF biofilm, mucus model was also investigated on the 60-day-old biofilms, to determine if magnetic gradient guided transport enhanced susceptibility. For this model, the cultures were prepared on agar as described above, however, $1 \mathrm{~mL}$ of either prepared pig mucin, aqueous alginate, or both were applied on top of the plated colonies. The drug or NP-drug impregnated disks were applied atop the barriers. Half of the agar plates were placed on top of a ring magnet composed of sintered neodymium, iron, and boron magnetic alloy blendgrade N45, having a Gauss rating of 13,500 Gauss, a pulling force of $282 \mathrm{lbs}$, an axial pole orientation, a $\mathrm{NiCuNi}$ coating, and a tolerance of \pm 0.002 inches. The magnets were placed below the agar plate for the entire overnight incubation.

\section{Determination of minimum inhibitory concentration determination}

For the MIC measurements, the compounds of interest (NPs, tobramycin, or NP-conjugates) were serially diluted in liquid growth media, inoculated from cultures grown for a specific period and incubated in sterile $2 \mathrm{~mL}$ vials overnight. The cultures were then grown overnight on a rotary shaker at $37{ }^{\circ} \mathrm{C}$ and $150 \mathrm{rpm}$. Optical density (OD) of liquid cultures was compared to a control cuvette containing only growth media, and ODs comparable to the growth media alone were considered inhibited growth.
OD typically increased with decreasing treatment concentrations, as the bacterial cells were increasingly able to differentiate at the decreasing treatment concentrations. The MIC was narrowed down by using the dilution series with even smaller increments of tobramycin concentration, ranging between its highest concentration that still allowed the growth of $P$. aeruginosa colonies and the next lowest concentration that completely inhibited their growth. The MIC measurements are schematically illustrated in Fig. 4.

To verify inhibition, an inoculation loop was used to plate samples from liquid cultures, having been incubated overnight with a known treatment concentration, and having an OD comparable to growth media alone. These agar plates were allowed to grow overnight at $37{ }^{\circ} \mathrm{C}$. MIC was determined by complete inhibition, defined by negative growth on agar as well as no apparent growth in liquid cultures determined by OD. For the control, sterile DI water was added to the aliquot of the culture, as opposed to an investigational compound. Due to the potential for interference of NPs with OD measurements, NPs were removed from solution, by magnetic separation, after inoculates were plated on agar, but prior to OD measurement.

\section{Comparison of biofilm inhibition in liquid cultures}

OD was used to determine the number of cells in each liquid culture. The biofilms were sonicated to detach them from the boiling stones prior to being transferred to cuvettes for the $\mathrm{OD}_{600}$ (optical density at a $600 \mathrm{~nm}$ wavelength) measurements. As before, the measurements

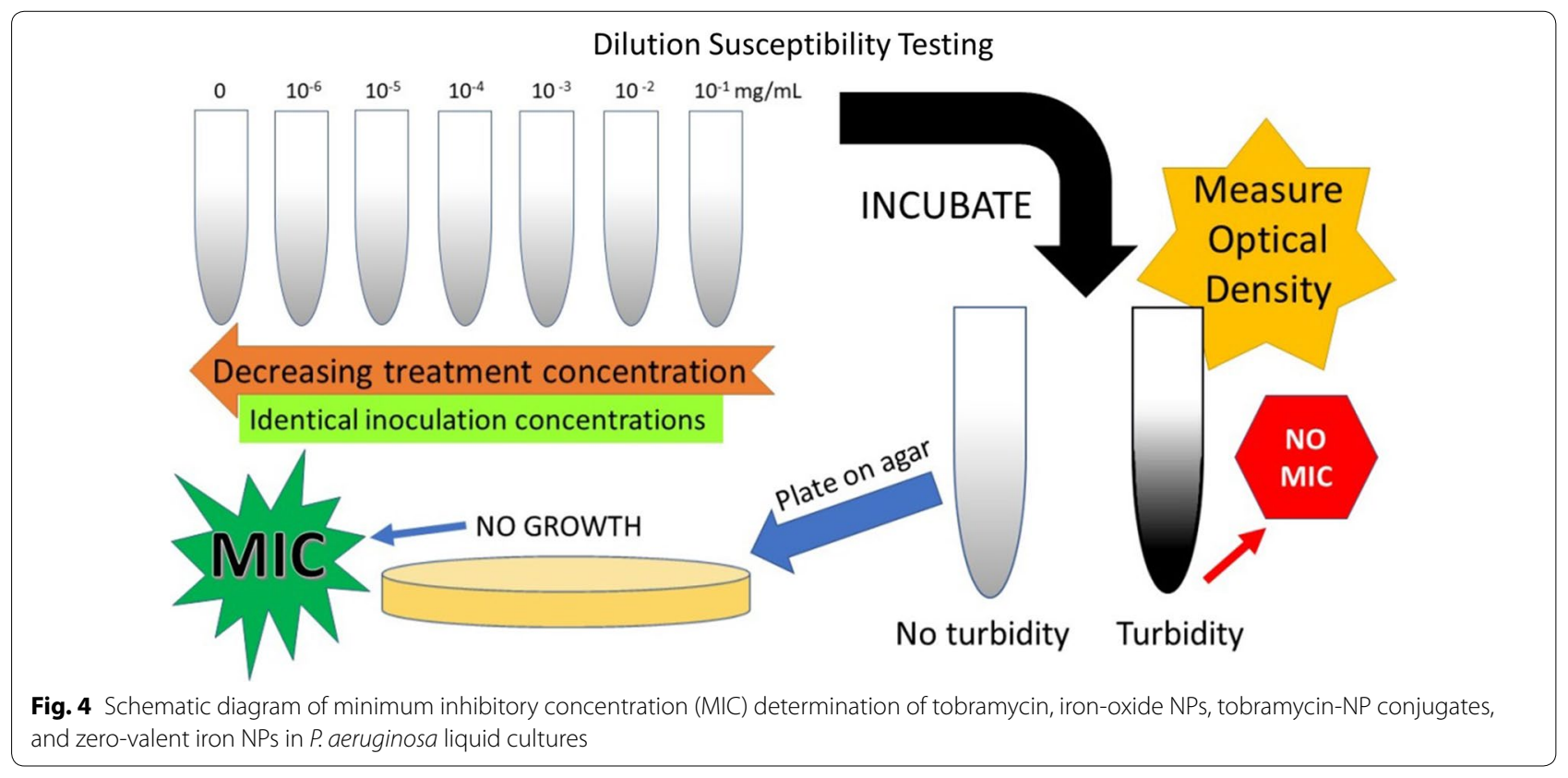


were taken against a blank cuvette containing only growth media.

\section{Graphical and statistical analysis}

Graphical and statistical analyses analysis of variance (ANOVA) were performed on Microsoft Excel and GraphPad Prizm ${ }^{\mathrm{TM}}$. Average values and standard deviations were calculated on Microsoft Excel ${ }^{\circledR}$ and ANOVA was performed on GraphPad Prizm ${ }^{\mathrm{TM}}$.

\section{Results}

\section{Nanoparticle characterization}

\section{Transmission electron microscopy}

TEM results (Fig. 5) show a spherical morphology, high monodispersity, and the iron cores measure approximately $16 \mathrm{~nm}$ in diameter, in agreement with the DLS results taken for NPs coated with oleate. Figure 6 shows a TEM image of an iron nitride NP, showing an oblong, rounded-rectangular morphology. The iron nitride NPs were approximately $15-45 \mathrm{~nm} \times 30-65 \mathrm{~nm}$ in size. It is important to note that the TEM analysis was difficult due to the strong magnetic interaction between the material and the electron beam. The strong magnetic properties of the sample caused the beam to oscillate, interfering with the analysis. Both the XRD and TEM show a body-centered tetragonal $(\mathrm{BCT})$ crystal system. This system would be expected for $\mathrm{Fe}_{16} \mathrm{~N}_{2}$, differentiating it from iron or iron oxide.

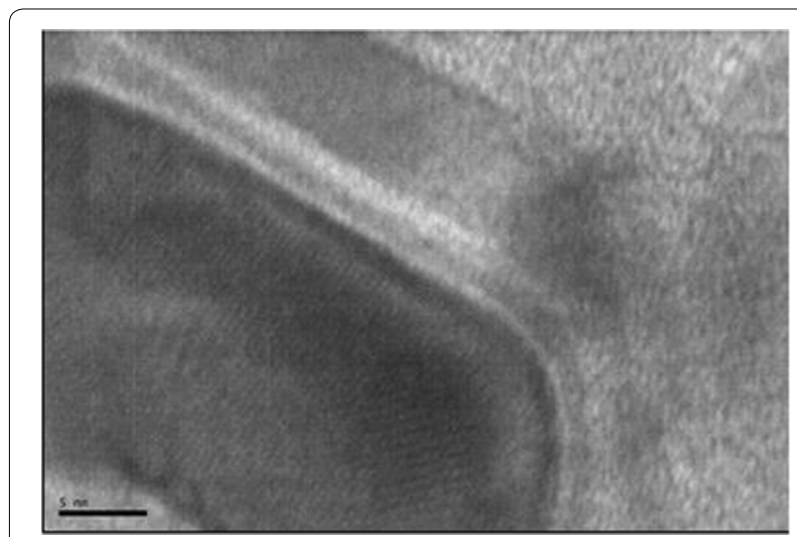

Fig. 6 HRTEM image of an iron nitride NP showing crystalline fringes, scale bar is $5 \mathrm{~nm}$

\section{Energy-dispersive $X$-ray spectroscopy}

Elemental composition of the $\mathrm{Fe}_{3} \mathrm{O}_{4}$ NPs was verified with EDS and is shown in Fig. 7. EDS confirms the presence of iron and oxygen in the nanocrystal structure. The carbon and copper peaks are from the carbon-coated copper grid.

\section{$X$-ray diffraction}

The XRD data for iron-oxide NPs (Fig. 8) suggest that the composition of the NPs is $70-80 \%$ spinel-phase iron oxide, which we attribute to magnetite. The remaining $20-30 \%$ appears to be $\mathrm{FeO}$ (wüstite) and $\alpha-\mathrm{Fe}_{2} \mathrm{O}_{3}$ (hematite), likely the result of surface oxidation of the alpha

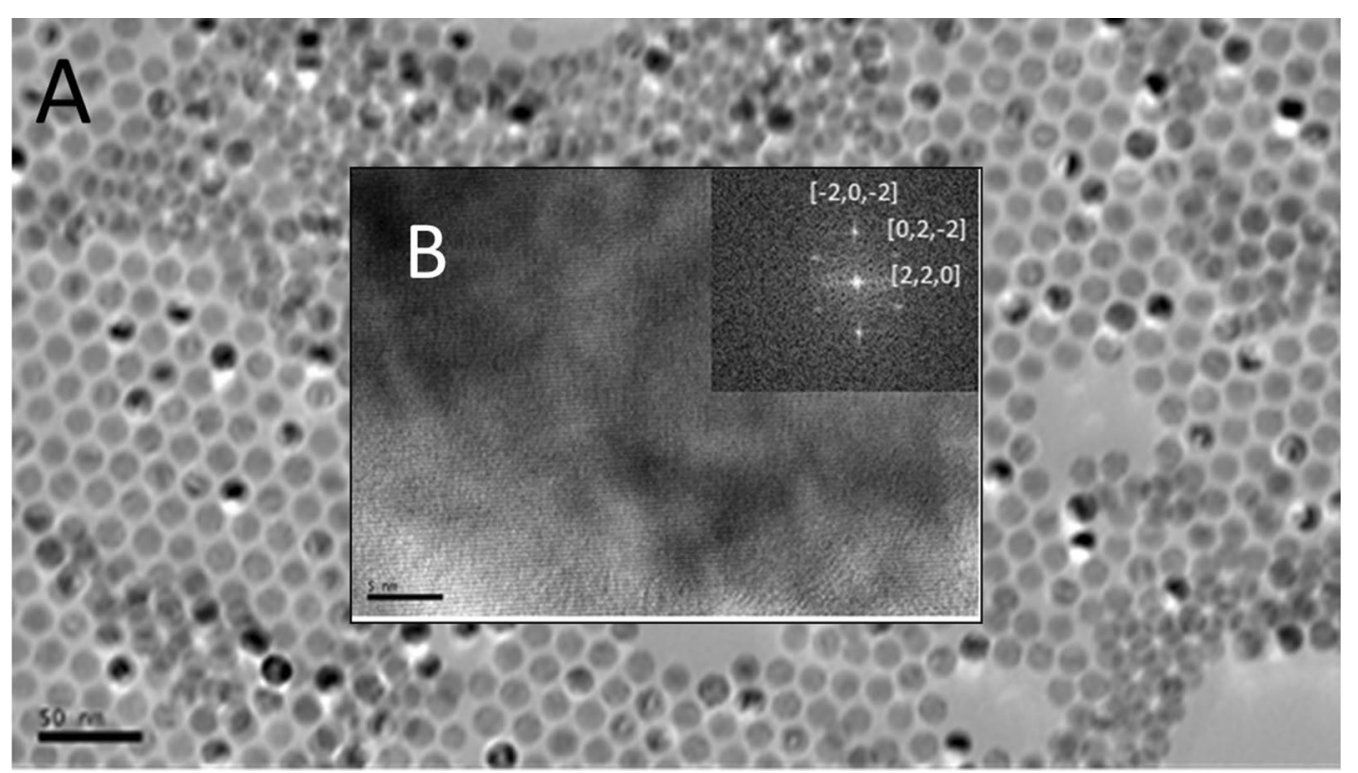

Fig. 5 TEM images of iron-oxide NPs prior to alginate capping. Image A, scale bar is $50 \mathrm{~nm}$, image B (insert) is a HRTEM image of crystal structure, scale bar $5 \mathrm{~nm}$, and FFT of fringing with crystal indices 


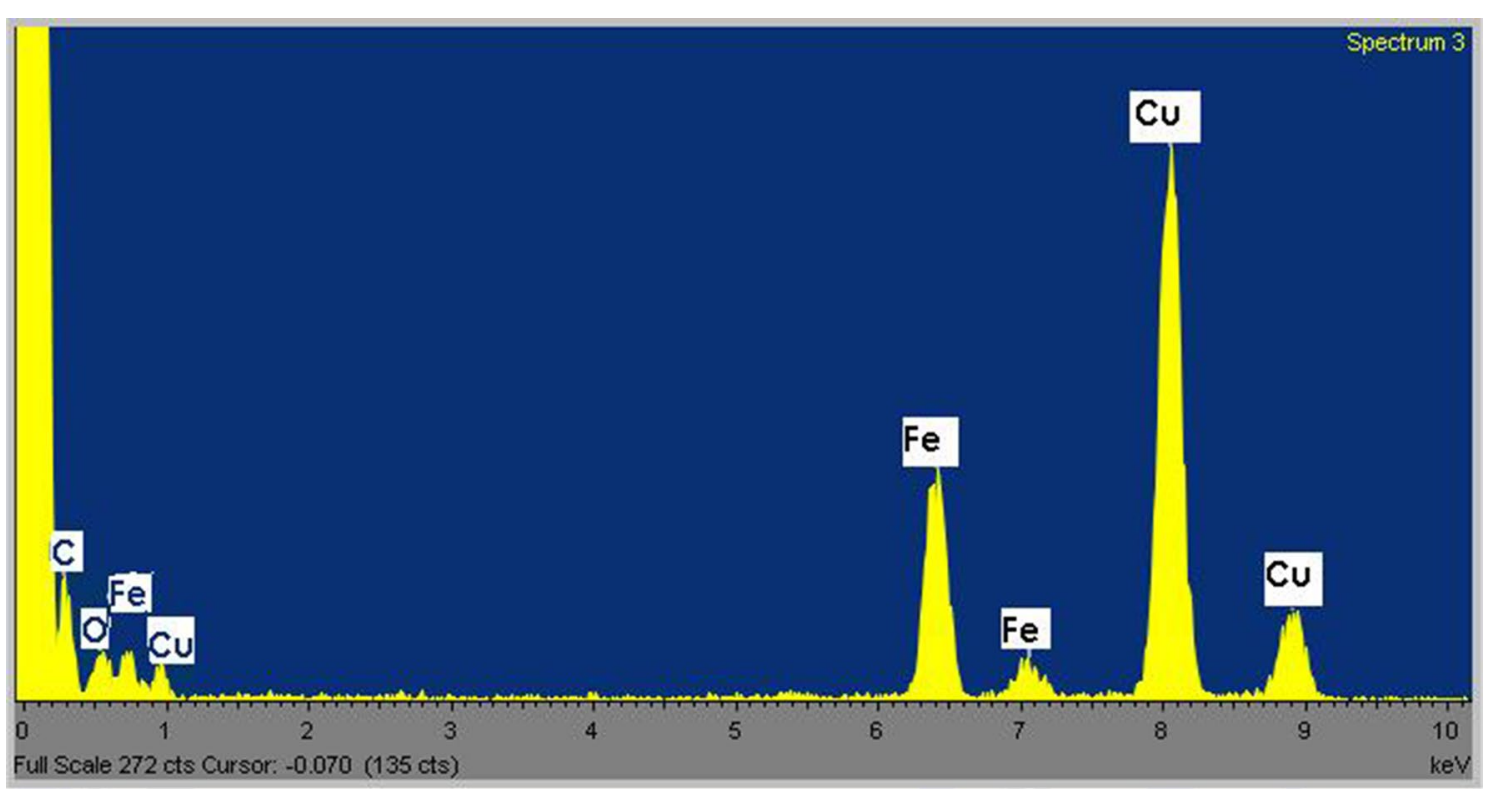

Fig. 7 Energy dispersive $x$-ray spectrum of iron-oxide NPs, showing elemental composition

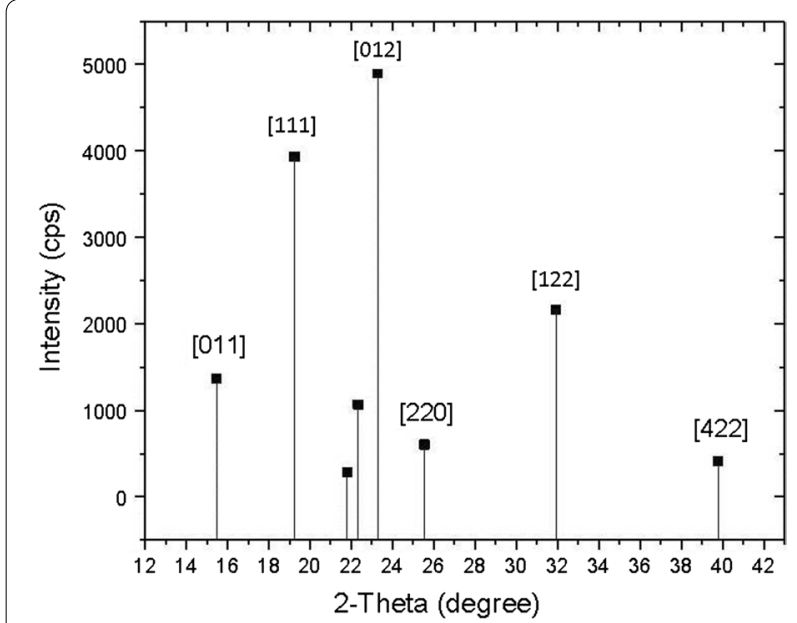

Fig. 8 Indexed magnetite peaks from powder $x$-ray diffraction pattern obtained with a Cu Ka $1.54 \AA$ source and a monochromator

iron. It is important to note that due to the similarity in space groups and lattice constants as well as significant peak-overlap among the iron-oxide phases, the oxidation state of iron-oxide, and thus differentiation between phases, are difficult to determine with absolute certainty using XRD. On XRD analysis, zero-valent iron shows a single strong peak at $\sim 44^{\circ}$ (not shown). XRD spectrum for the uncapped iron nitride NP sample can be seen in Fig. 9. The Jade software automatched the spectrum to the iron nitride (martensite) phases $\alpha^{\prime}-\mathrm{Fe}_{8} \mathrm{~N}, \mathrm{ICDD} / \mathrm{ICSD}$ card number 01-070-6150 and $\alpha$ "-Fe ${ }_{16} \mathrm{~N}_{2}$, ICDD/ICSD card number 01-078-1865, both tetragonal crystals with lattice constants $a=5.71 \AA, b=5.71 \AA, c=6.016 \AA$ and $a=5.72 \AA, b=5.72 \AA, c=6.29 \AA$, respectively. The scan also reveals some magnetite $\left(\mathrm{Fe}+2 \mathrm{Fe}_{2}+3 \mathrm{O}_{4}\right)$, ICDD/ ICSD card number 00-019-0629, which is a cubic crystal with lattice constants $a=8.38 \AA$, $b=8.38 \AA, c=8.38 \AA$. This iron oxide likely resulted from surface oxidation of the uncapped NP sample which was set onto the slide using ethyl alcohol, chloroform, and heat.

\section{Dynamic light scattering}

DLS results on OA-capped NPs right after synthesis returned an average diameter of $\sim 16 \mathrm{~nm}$ (Fig. 10), in agreement with the TEM observations. PEG-5000 has a theoretical average length of $\sim 30 \mathrm{~nm}$, however it is important to note that the polymer length is just an average value, in addition the polymer chain can bend and twist resulting in a range of measured values. In our experiments, the succinylated PEG-5000 capping increased the hydrodynamic size of the NPs from 16 to $\sim 41 \mathrm{~nm}$.

Alginate capping, using the natural alginate, also having a range of polymer lengths, increased the hydrodynamic size of the NPs to $229.71 \mathrm{~nm}$ (Fig. 11). Tobramycin conjugation did not alter hydrodynamic size, as expected, due to the small sizes of both the tobramycin molecule and the crosslinker. Tobramycin conjugation was confirmed by FTIR spectroscopy. 


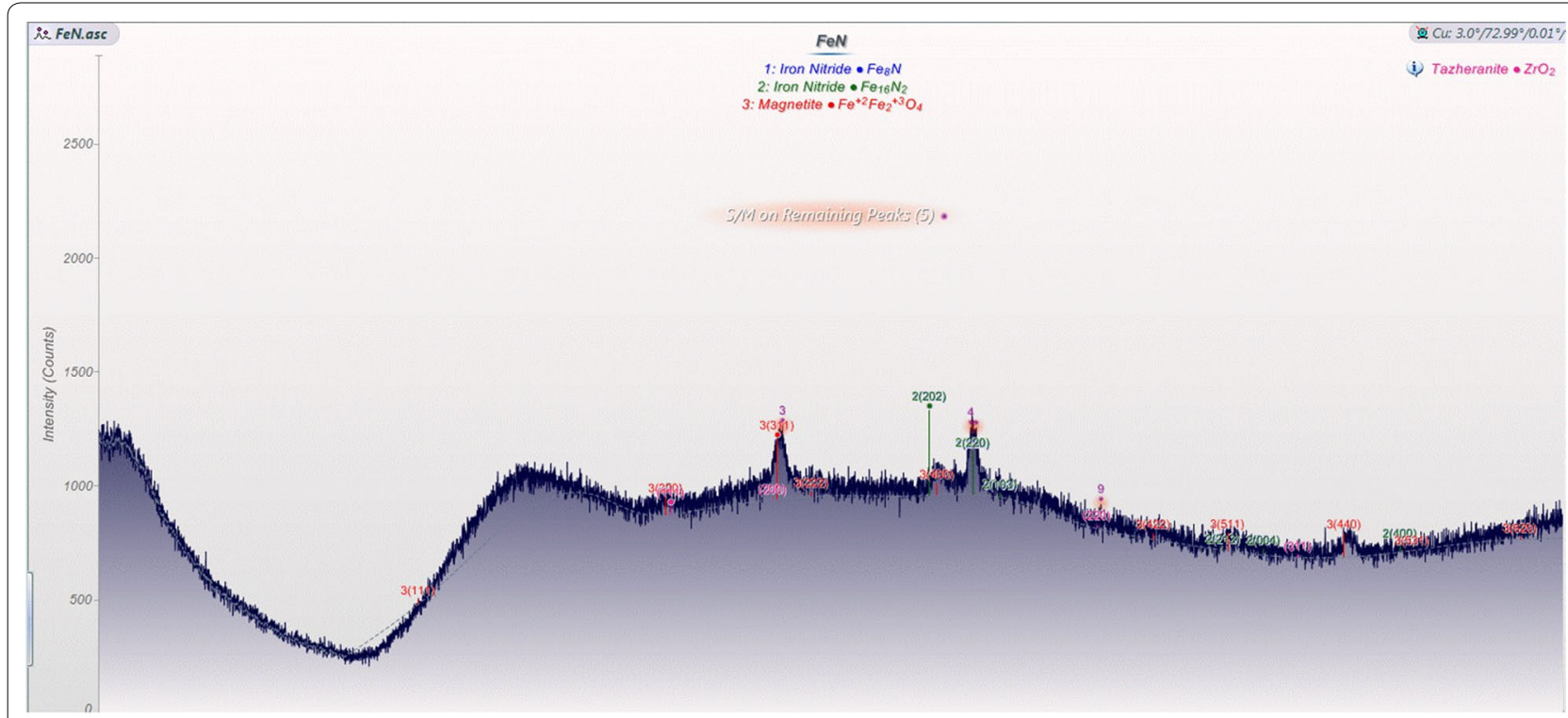

Fig. 9 XRD spectrum of iron nitride NPs taken with a Cu Ka $1.54 \AA$ A source and a monochromator

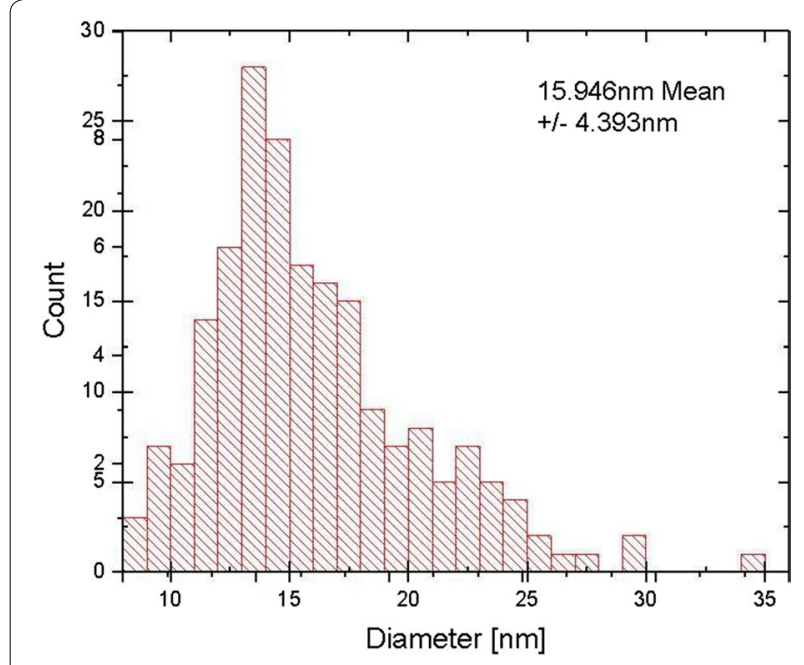

Fig. 10 DLS size-distribution histogram of iron-oxide NPs prior to polymer coating

Table 1 contains a summary of DLS results for all NPs used in this study.

\section{Magnetic characterization}

A typical feature in magnetic NPs is their irreversible ferromagnetic behavior below the blocking temperature $T_{B}$ and reversible magnetization above it, caused by superparamagnetic behavior of the NPs. Below $T_{B}$, the Néel relaxation time $\tau_{N}$ is larger than the measurement time $\tau_{\mathrm{m}}$ (typically $100 \mathrm{~s}$ ), and magnetization depends strongly on the field history. Above $T_{B}$, magnetization is strongly affected by thermal fluctuations $\left(\tau_{m}>T_{N}\right)$, making FC and ZFC curves coincide. Therefore, for a given measurement time $\tau_{m}$, hysteretic behavior observed below $T_{B}$ would not be observed above $T_{B}$. The NPs displayed no hysteresis (no coercivity) under full magnetization $v s$ field strength $(\mathrm{M} / \mathrm{H})$ sweep at $293 \mathrm{~K}$ (Fig. 12), a typical feature of superparamagnetic materials.

The DC $\left(\tau_{\mathrm{m}}=100 \mathrm{~s}\right)$ magnetization of the ferrofluid samples was measured with a DC field of 100 Oe in the temperature range between 9 and $350 \mathrm{~K}$ using a Quantum Design $^{\mathrm{TM}}$ magnetic property measurement system (MPMS) superconducting quantum interference device (SQUID). In the entire temperature range up to $350 \mathrm{~K}$, the $\mathrm{Fe}_{16} \mathrm{~N}_{2} \mathrm{NP}$ samples demonstrated strong ferromagnetic behavior, as evidenced by the gap between the ZFC and FC curves persisting even at $350 \mathrm{~K}$. From the ZFC curve, we can loosely estimate $\mathrm{T}_{\mathrm{B}}$ to be $\sim 350 \mathrm{~K}$, but even above that temperature equilibrium magnetization of the NP sample was not reached. Superparamagnetic behavior of the $\mathrm{Fe}_{16} \mathrm{~N}_{2}$ NP samples was confirmed in magnetic

Table 1 Summary of DLS results

\begin{tabular}{ll}
\hline Material & Hydrodynamic size \\
\hline Iron-oxide:oleate NPs & $16 \mathrm{~nm} \pm 4.4 \mathrm{~nm}$ \\
Iron-oxide:PEG NPs & $40.65 \mathrm{~nm} \pm 0.83 \mathrm{~nm}$ \\
Iron-oxide:alginate NPs & $229.71 \mathrm{~nm}$ \\
Iron-nitride:uncapped NPs & $39.25 \mathrm{~nm} \pm 21.40 \mathrm{~nm}$ \\
Iron-nitride:alginate NPs & $267.6 \pm 128.6 \mathrm{~nm}$ \\
Zero-valent iron:alginate NPs & $241.571 \pm 126.4 \mathrm{~nm}$ \\
\hline
\end{tabular}




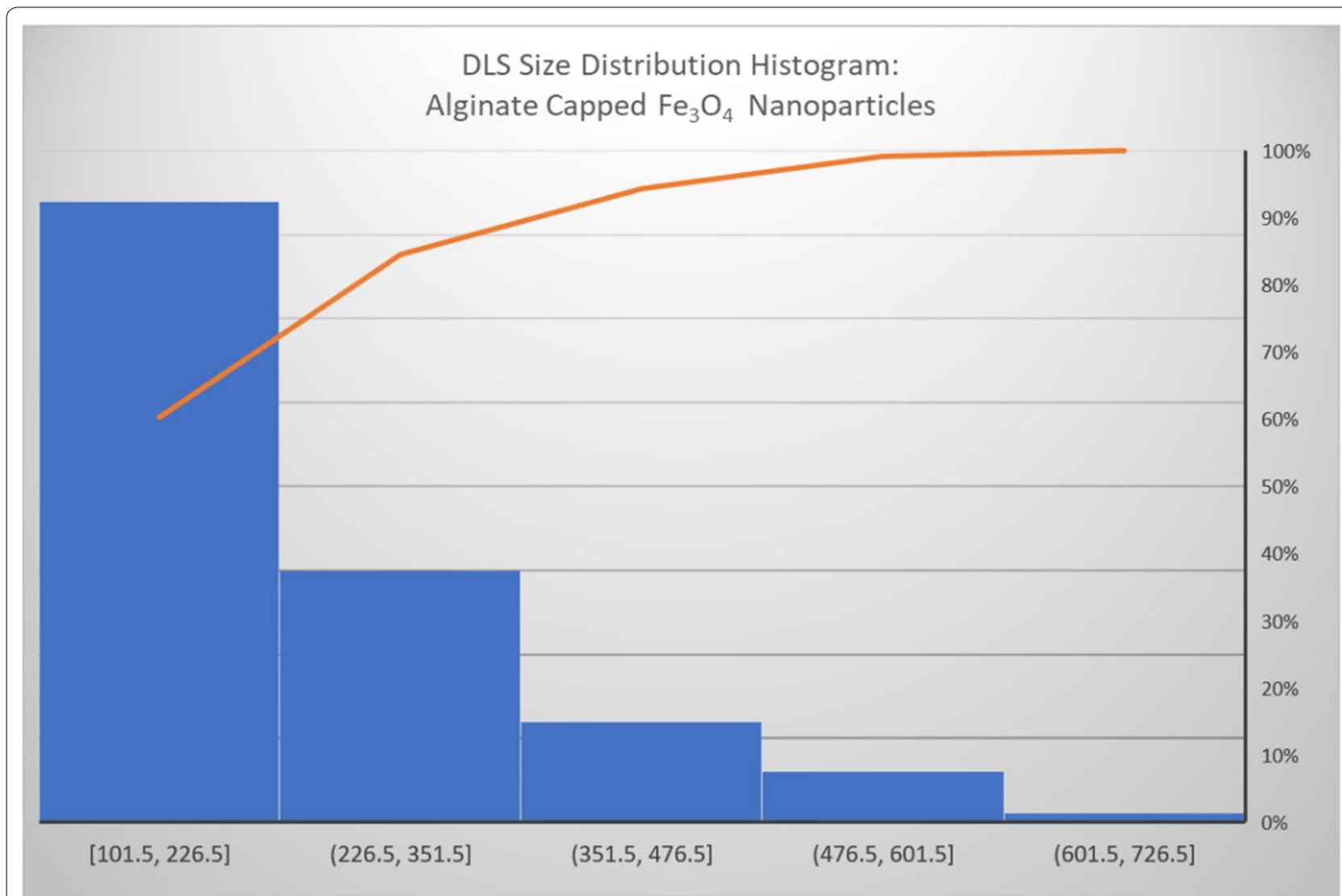

Fig. 11 DLS size distribution showing average hydrodynamic size of iron-oxide NPs after alginate capping
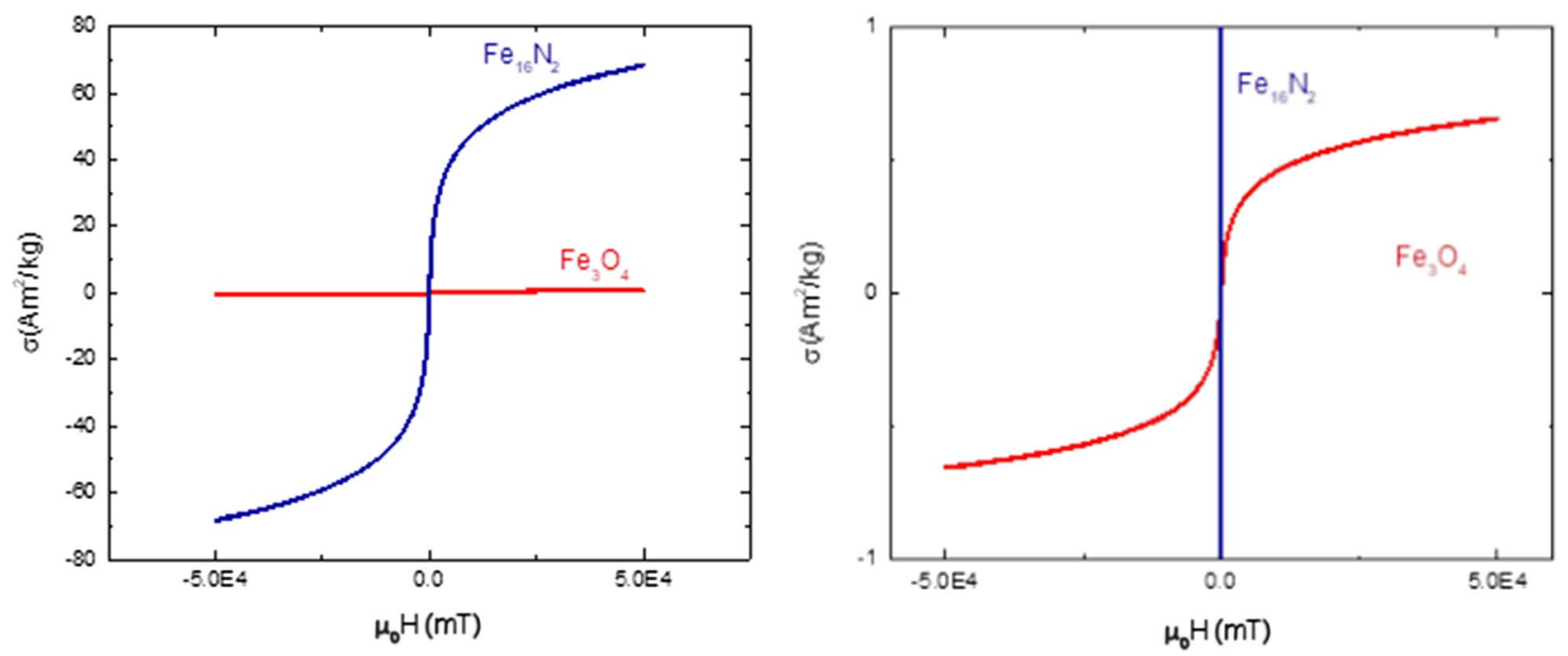

Fig. 12 Comparison of hysteresis loops of nanocrystalline samples of iron oxide (red) and iron nitride (blue) of similar grain size, showing the significantly stronger magnetic properties of iron nitride. Left image shows entire hysteresis loop of iron nitride. Right image is a close up of the same, showing hysteresis loop of iron oxide 
hysteresis measurements. Consistent with the results of DC magnetization measurements, magnetic hysteresis measurements at $293 \mathrm{~K}$ performed on $\mathrm{Fe}_{16} \mathrm{~N}_{2} \mathrm{NPs}$ found no coercivity. We were unable to find $\mathrm{M}_{\text {sat }}$ with the field strengths presently available. Extrapolating the line gives a loose estimate of $M_{\text {sat }} \sim 100 \mathrm{emu} / \mathrm{g}$. The same measurement performed on the iron-oxide NP samples revealed a blocking temperature of approximately $150 \mathrm{~K}$, far below the measured value for the iron nitride sample (Fig. 13).

\section{Zeta potential results}

Table 2 summarizes the zeta potential measurements for the listed samples. The best results have been obtained for the NPs coated with alginate. It is possible that even higher colloidal stability could be achieved with a thicker alginate coating, leading to a more negative zeta potential. However, it is important to note that a larger sized particles may have more difficulty diffusing through the pores in the mucus/biofilms. It appears that sufficient

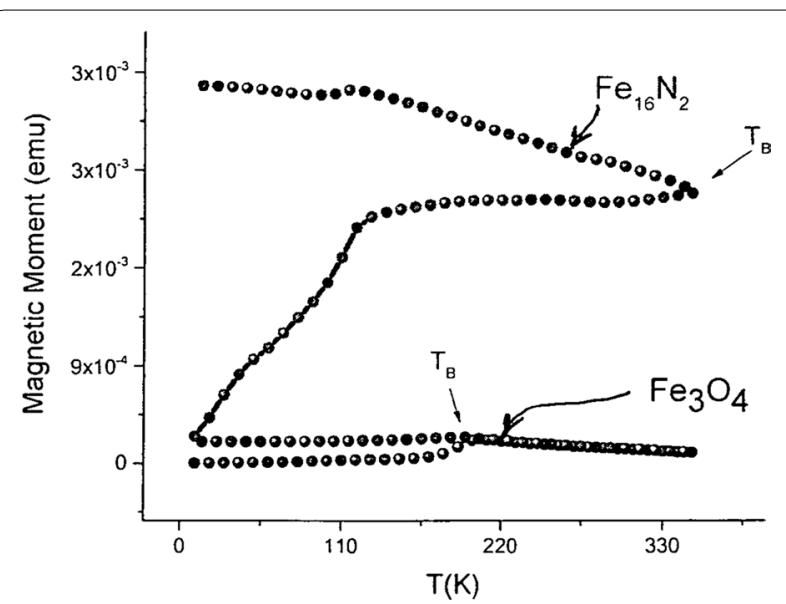

Fig. 13 Magnetization vs temperature for iron-oxide and iron-nitride NPs under zero-field cooled (lower curves) and field cooled (upper curves) conditions. The magnetization of the ferrofluid samples was measured with a DC field of $100 \mathrm{Oe}\left(\tau_{\mathrm{m}}=100 \mathrm{~s}\right)$ in the temperature range between $9 \mathrm{~K}$ and $350 \mathrm{~K}$

Table 2 Summary of zeta potential results

\begin{tabular}{llll}
\hline Material & Solvent & $\begin{array}{l}\text { Zeta } \\
\text { potential } \\
(\mathbf{m V})\end{array}$ & $\begin{array}{l}\text { Standard } \\
\text { deviation } \\
(\mathbf{m V})\end{array}$ \\
\hline Iron-oxide:oleic acid NPs & Chloroform & -11.1 & 7.46 \\
Iron-oxide:PEG NPS & DI water & -4.23 & 6.92 \\
Iron-oxide:alginate NPs & DI water & -31.5 & 6.33 \\
Iron-nitride:alginate NPs & DI water & -25.2 & 7.63 \\
Zero-valent iron:alginate NPs & DI water & -22.1 & 5.8 \\
Iron oxide:alginate:tobra NPS & DI water & -15.1 & 7.18 \\
\hline
\end{tabular}

charge shielding, and acceptable colloidal stability has been achieved and is balanced with the desired hydrodynamic size $(\sim 250 \mathrm{~nm})$.

\section{FTIR and confirmation of tobramycin conjugation}

The presence of an amide stretch, visible on FTIR at $1630-1680 \mathrm{~cm}^{-1}$ was used to verify the success of the crosslinking procedure. Loading efficiency of tobramycin calculated as mass of NP conjugates/mass of alginate-capped NPs was found to be $\sim 2 \%$.

\section{Motility testing results Motility testing}

P. aeruginosa was not found to be motile after an overnight incubation in liquid growth media. Cultures taken from biofilms were found to exhibit motility after 3 -days of growth (see image results in Fig. 14). These findings attest to the increase in genetic diversity in the established biofilms.

Susceptibility results determined via disk diffusion method Figure 14 shows the disk diffusion experiment before and after incubation and the motility testing results, all performed using solid agar. Disk diffusion results for tobramycin were interpreted based on the 2019 CLSI breakpoints for tobramycin in $P$. aeruginosa [178], in which the mass of tobramycin on the disk is $10 \mu \mathrm{g}$ and a disk diameter of $\geq 15 \mathrm{~mm}$ is susceptible (S), $13-14 \mathrm{~mm}$ is intermediate (I) and $\leq 12 \mathrm{~mm}$ is resistant (R). Since there exist no standards for the investigation of iron oxide nanoparticle susceptibility in any microbes, we used the same cutoff values as for tobramycin in order to maintain consistency. We also investigated a range of concentrations of tobramycin, NPs, and NP-conjugates in order to determine susceptibility range. Over time, the disk diffusion results (Table 3), taken together with the MIC results, demonstrate that the tobramycin susceptibility decreases and resistance increases as the colonies are allowed to grow in biofilm mode for longer periods of time, despite being tobramycin naïve. Therefore, this is not due to exposure-related resistance development. It is important to note that the observed increase in resistance is not due to a larger initial amount of CFU's in the 60-day old biofilms, because cultures were diluted and identical concentrations of CFUs were used for inoculation and plating for all time periods. These findings suggest that the age of the infection alone (i.e., establishment of a chronic infection) contributes to resistance. This is possibly due to broader genetic diversity in the population. No comparable increase in resistance over time was observed for the NP samples investigated, suggesting that a genetic 

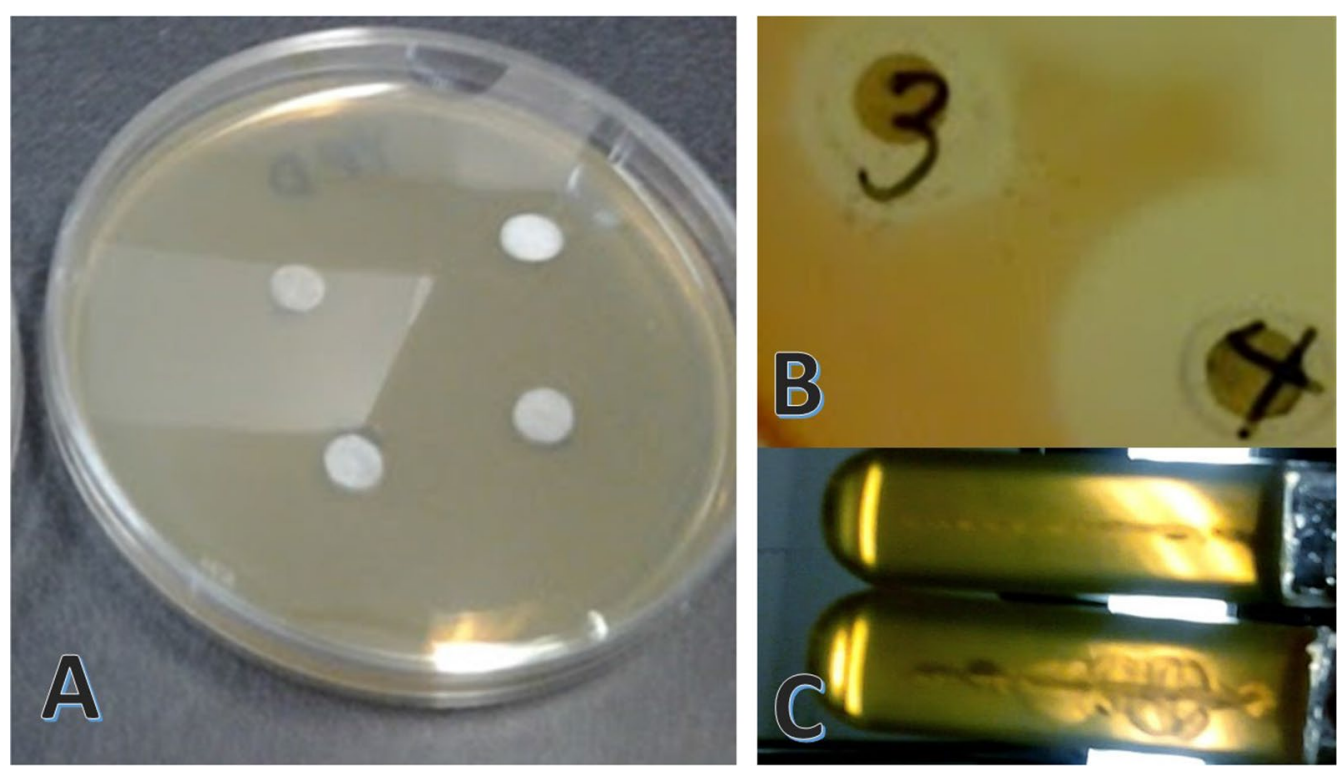

Fig. 14 Agar cultures used for susceptibility testing. A) Agar plate with impregnated disks prior to overnight incubation. B) Image shows zone of inhibition (ZOI) halo around disk impregnated with antimicrobial agent of interest; a positive susceptibility result. C) Motility testing results in agar stab cultures after incubation; upper tube is a negative motility result and lower tube is a positive motility result

Table 3 Susceptibility of $P$. aeruginosa biofilms to various treatments after 3 and 60 days of growth, determined by disk diffusion

\begin{tabular}{|c|c|c|c|}
\hline Material & Dose on disk ( $\mu \mathrm{g})$ & $\begin{array}{l}\text { ZOI }(\mathrm{mm}) \\
\text { day } 3\end{array}$ & $\begin{array}{l}\text { ZOI }(\mathrm{mm}) \\
\text { day } 60\end{array}$ \\
\hline \multirow{3}{*}{$\mathrm{Fe}_{3} \mathrm{O}_{4} \mathrm{NPS}^{\dagger}$} & 10 & $22 / S$ & $21 / S$ \\
\hline & 5 & $17.5 / \mathrm{S}$ & $16 / S$ \\
\hline & 2.5 & $11 / \mathrm{R}$ & $10 / R$ \\
\hline \multirow[t]{3}{*}{$\mathrm{Fe}_{3} \mathrm{O}_{4} @ P E G N P s$} & 10 & O/R & $0 / R$ \\
\hline & 5 & O/R & $0 / R$ \\
\hline & 2.5 & O/R & O/R \\
\hline \multirow[t]{3}{*}{$\mathrm{Fe}_{3} \mathrm{O}_{4} @ \mathrm{ALG} N P s$} & 10 & $22 / S$ & $22 / 5$ \\
\hline & 5 & $16 / S$ & $15 / S$ \\
\hline & 2.5 & $10 / R$ & $8 / \mathrm{R}$ \\
\hline \multirow[t]{3}{*}{$\mathrm{Fe}_{3} \mathrm{O}_{4} @ \mathrm{ALG}: \mathrm{TOBRA}$ NPs } & 10 & $23 / S$ & $22 / S$ \\
\hline & 5 & $11 / \mathrm{R}$ & $15 / 1$ \\
\hline & 2.5 & $7 / \mathrm{R}$ & $5 / \mathrm{R}$ \\
\hline \multirow[t]{3}{*}{ ZVFe@ALG NPs } & 10 & $25 / S$ & $24 / S$ \\
\hline & 5 & $21 / S$ & $22 / S$ \\
\hline & 2.5 & $20 / 5$ & $20 / 5$ \\
\hline \multirow[t]{3}{*}{ Tobramycin } & $10^{*}$ & 10/R & O/R \\
\hline & $100^{* *}$ & $25 / R^{* *}$ & $15 / R^{* *}$ \\
\hline & $1000^{* *}$ & $35 / R^{* *}$ & $32 / R^{* *}$ \\
\hline
\end{tabular}

Interpretation: $R$ resistant, I bintermediate, $S$ susceptible, $Z O I$ zone of inhibition, PEG polyethylene glycol, ALG alginate, TOBRA tobramycin, ZVFe zero-valent iron

†Uncapped NPs. *CLSI breakpoint for susceptibility of tobramycin by disk diffusion is $10 \mu \mathrm{g}$. Therefore, all colonies are found to be tobramycin resistant by CLSI standards. **Higher tobramycin doses in the disk were investigated to determine whether any susceptibility existed at higher doses. At present, there are no CLSI values/ breakpoints for NPs as antimicrobial agents resistance mechanism to counter the action of the compound may not exist. We can speculate that the mechanism of action of the iron-oxide NPs is not based on inhibition of genes or bacterial protein synthesis, which implies the toxicity may not be prokaryote-specific.

For the iron-oxide NPs alone, we found that inhibition of established biofilms on agar plates was observed for low concentrations. When capped with alginate, the inhibition remained low even though part of the mass of this core-shell type NP consists of non-bioactive alginate. In the case of iron-oxide NPs capped with PEG, no inhibition was observed, possibly because the non-biodegradable nature of the capping agent may keep the iron from interacting directly with the bacteria (see Table 3 ). If the iron ions contribute to the toxicity, it may be possible that, in this case, they were not distributed to the colonies, and therefore, could not inhibit bacterial growth.

Regardless of the mechanism, which has yet to be established, these findings demonstrate that the crucial role of the capping agent to the impartation of antimicrobial properties. Therefore, the capping agent also contributes to or negates the toxicity of this material. We can speculate that a complete PEG cap may also reduce the toxicity of NPs known to exhibit cytotoxic effects in vivo, since it appears to limit interaction with the cells, at least in this short exposure time frame.

Even at high concentrations, we might expect to observe some inhibition due to incomplete coverage, however, that is not the case. In the case of iron-oxide 
NPs conjugated to tobramycin, we find that the bacterial inhibition at these concentrations mirrors the inhibition trend of iron-oxide NPs alone. It is important to note that these findings are characteristic of this particular strain, after this period of growth, and its susceptibility to tobramycin. One previous study found that after a $1000 \mu \mathrm{g} / \mathrm{mL}$ concentration of tobramycin was applied to established biofilms, a significant proportion of the bacterial cells were still viable after $12 \mathrm{~h}$ [181]. This group also reported that planktonic cells taken from the same strain was completely killed by only $50 \mu \mathrm{g} / \mathrm{mL}$. Another relevant study reports the MIC from their clinical isolates to be $8 \mu \mathrm{g} / \mathrm{mL}$ [130]. These published findings suggest a huge theoretical therapeutic dose ranging from 8 to more than $1000 \mu \mathrm{g} / \mathrm{mL}$. MIC and susceptibilities appear to differ dramatically from strain to strain and in planktonic vs biofilm communities. Therefore, it is probable that these susceptibilities may also differ from strain to strain and under different growth conditions.

\section{Inhibitory concentration of tobramycin}

The MIC of tobramycin in this strain of $P$. aeruginosa was determined for several time points in liquid and biofilm cultures, and found to be $10-15 \mu \mathrm{g} / \mathrm{mL}$ for planktonic cells grown overnight in liquid broth, $32 \mu \mathrm{g} / \mathrm{mL}$ for 3-day old biofilm cells, $50 \mu \mathrm{g} / \mathrm{mL}$ for 10-day old biofilms and $93.7 \mathrm{mg} / \mathrm{mL}$ for 60-day old biofilms (Fig. 15).
All biofilm colonies were maintained in liquid broth on sterile boiling stones, having the broth was replaced daily. The MIC of tobramycin differs significantly from strain to strain and when comparing planktonic vs biofilm cells, as well as biofilm growth time. These trends were not observed for shorter periods of growth. These findings add merit to our longer-term growth period for the establishment of biofilm colonies. According to the breakpoints recommended by the CLSI for determination of MIC; inhibition at a concentration $\leq 4 \mu \mathrm{g} / \mathrm{mL}$ of tobramycin means the strain is susceptible; inhibition at a concentration of $8 \mu \mathrm{g} / \mathrm{mL}$ is intermediate; and inhibition at concentrations $\geq 16 \mu \mathrm{g} / \mathrm{mL}$ means the strain is tobramycin resistant [178]. Therefore, according to the CLSI breakpoints for interpretation of MIC, these cultures were never found to be susceptible to tobramycin. The biofilm cultures were found to be tobramycin-resistant and becoming more resistant over time.

\section{CF mucin alginate barrier model}

The CF model, in which artificial mucin and alginate barriers were applied over the agar-grown colonies cultured from established 60-day old biofilms, reveals that application of an external magnetic field enhances susceptibility to the iron-oxide NPs and NP-drug conjugates, possibly by promoting transport across the two barriers. For this study, $50 \mathrm{mg} / \mathrm{mL}$ concentrations of NPs and

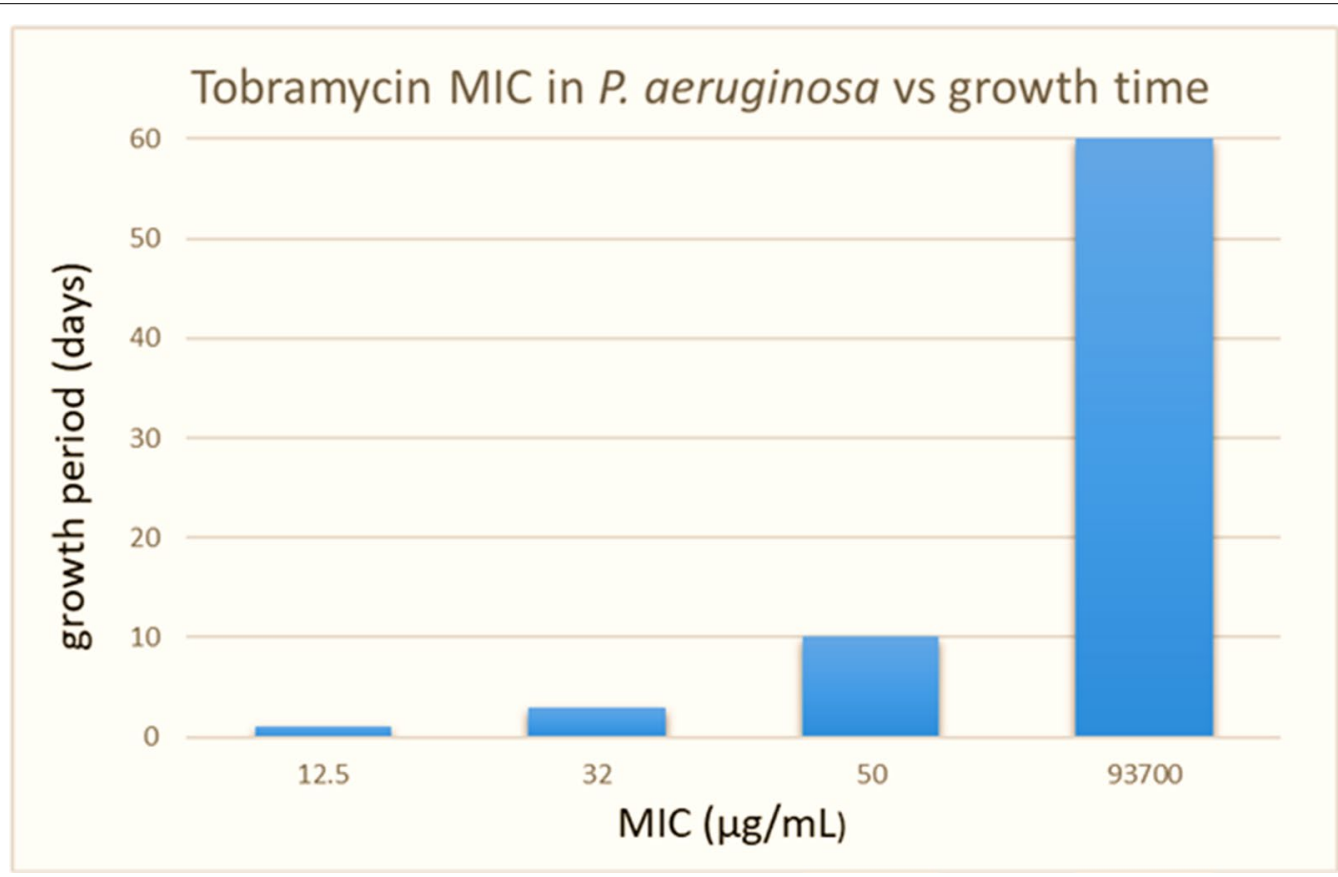

Fig. 15 Minimum inhibitory concentration (MIC) of tobramycin on P. aeruginosa colonies as a function of growth time. Note that the cutoff concentration for susceptibility of $P$. aeruginosa to tobramycin in liquid cultures is $\leq 4 \mu \mathrm{g} / \mathrm{mL}$. Therefore, none of the cultures are susceptible to tobramycin by CLSI standards 
Table 4 Susceptibility of $P$. aeruginosa colonies beneath mucin, alginate, or alginate and mucin barriers, determined by disk diffusion

\begin{tabular}{llll}
\hline Disk no./compound & Mucin & Alginate & Alginate + Mucin \\
\hline 1. $\mathrm{Fe}_{3} \mathrm{O}_{4} \mathrm{NPs}+10 \mu \mathrm{g}$ & $14 / \mathrm{l}$ & $0 / \mathrm{R}$ & $22 / \mathrm{S}$ \\
2. $\mathrm{Fe}_{3} \mathrm{O}_{4} @ \mathrm{ALG}: \mathrm{TOBRA} 10 \mu \mathrm{g}$ & $0 / \mathrm{R}$ & $0 / \mathrm{R}$ & $0 / \mathrm{R}$ \\
3. Tobramycin 10 $\mu \mathrm{g}$ & $0 / \mathrm{R}$ & $0 / \mathrm{R}$ & $0 / \mathrm{R}$ \\
4. Tobramycin $100 \mu \mathrm{g}^{* *}$ & $11 / \mathrm{R}^{* *}$ & $14 / \mathrm{R}^{* *}$ & $5 / \mathrm{R}^{* *}$ \\
5. Tobramycin $200 \mathrm{mg}^{* *}$ & $30 / \mathrm{R}^{* *}$ & $35 / \mathrm{R}^{* *}$ & $30 / \mathrm{R}^{* *}$ \\
\hline
\end{tabular}

Disk diffusion method was used. Minimum concentrations demonstrating susceptibility in previous disk diffusion studies were used for NPs and NP-tobramycin conjugates. ${ }^{\dagger}$ Uncapped NPs, ALG: alginate, TOBRA: tobramycin

* Maximum CLSI cutoff concentration for susceptibility of tobramycin $10 \mu \mathrm{g}$ absorbed onto disk

** Corresponding to experimentally determined susceptibility, these doses of tobramycin shown were up to five orders of magnitude higher than the CLSI standard dose for disk diffusion. Therefore, although inhibition was observed, these colonies were tobramycin resistant by CLSI standard

Table 5 Susceptibility of $P$. aeruginosa colonies beneath mucin, alginate, or alginate and mucin barriers with external magnetic field application

\begin{tabular}{llll}
\hline $\begin{array}{l}\text { Disk no. } \\
\text { compound }\end{array}$ & Mucin barrier & Alginate barrier & $\begin{array}{l}\text { Mucin +alginate } \\
\text { barriers }\end{array}$ \\
\hline $\begin{array}{l}\text { 1. } \mathrm{Fe}_{3} \mathrm{O}_{4} \mathrm{NPS} \dagger \\
10 \mu \mathrm{g}\end{array}$ & $30 / \mathrm{l}$ & $0 / \mathrm{R}$ & $20 / \mathrm{S}$ \\
$\begin{array}{l}\text { 2. } \mathrm{Fe} \mathrm{O}_{4} @ \\
\mathrm{ALG}: T O B R A\end{array}$ & $25 / \mathrm{R}$ & $19 / \mathrm{R}$ & $14 / \mathrm{R}$ \\
$\begin{array}{l}\text { 3. Tobramycin* } \\
\text { 4. Tobramycin }\end{array}$ & $0 \mathrm{R}$ & $0 / \mathrm{R}$ & $0 / \mathrm{R}$ \\
$100 \mu \mathrm{Hg}^{* *}$ & $10 / \mathrm{R}^{* *}$ & $12 / \mathrm{R}^{* *}$ & $0 / \mathrm{R}^{* *}$ \\
$\begin{array}{l}\text { 5. Tobramycin } \\
200 \mathrm{mg}^{* *}\end{array}$ & $32 / \mathrm{R}^{* *}$ & $30 / \mathrm{R}^{* *}$ & $20 / \mathrm{R}^{* *}$ \\
\end{tabular}

Disk diffusion method was used. Minimum concentrations demonstrating susceptibility in previous disk diffusion studies were used for NPs and NP-tobramycin conjugates. fUncapped NPs, ALG alginate, TOBRA tobramycin * Maximum CLSI cutoff concentration for susceptibility of tobramycin $10 \mu \mathrm{g}$ absorbed onto disk

** Corresponding to experimentally determined susceptibility, these doses of tobramycin were up to five orders of magnitude higher than the CLSI standard dose for disk diffusion. Therefore, these colonies were tobramycin resistant by CLSI standard

NP-conjugate solution were applied to the disk, such that each disk contained $50 \mu \mathrm{g}$ of test article. The results without (Table 4) and with (Table 5) magnetic field application demonstrate zero susceptibility to tobramycin alone. No CLSI breakpoints exist for NPs or NP conjugates at present, however, the CLSI cutoff values for determination of $P$. aeruginosa susceptibility to tobramycin with $10 \mu \mathrm{g}$ absorbed onto a disk are $\geq 15$ susceptible, 13-14 intermediate, and $\leq 12$ resistant [178]. The same parameters were used for interpretation of the NP and NPconjugate results. Tables 4 and 5 demonstrate the highly statistically significant contribution of the external magnetic field in enhancing susceptibility to the test articles. More work is needed to determine the exact role of the magnetic field in addition to determining the minimum or maximum field strength necessary to achieve maximum susceptibility. It is possible that the pulling force of the magnet may relate in some way to the thickness of the biofilm and mucus barriers.

\section{Biofilm inhibition in liquid cultures}

Biofilm inhibition and MIC of liquid cultures was determined by taking a standardized aliquot from established 60-day old biofilm communities, inoculating a standardized volume of liquid broth containing the desired amount of drug or broth only (for the negative control), and then growing for $24-\mathrm{h}$. $\mathrm{OD}_{600}$ was determined against a blank cuvette, containing broth only. The $\mathrm{OD}_{600}$ of the negative control samples (containing only inoculated broth) was determined to be 0.22 to 0.24 . This result is slightly higher than the lowest treatment concentration $\left(8 \times 10^{-6} \mathrm{mg} / \mathrm{mL}\right)$. Due to the lack of prior art suggesting an inhibitory concentration, it was necessary to investigate a large range of concentrations to determine MIC. The range used was $17.35 \mathrm{mg} /$ $\mathrm{mL}$ to $8 \times 10^{-6} \mathrm{mg} / \mathrm{mL}$, in a consistent volume, determined by serial dilution, as the graph in Fig. 16

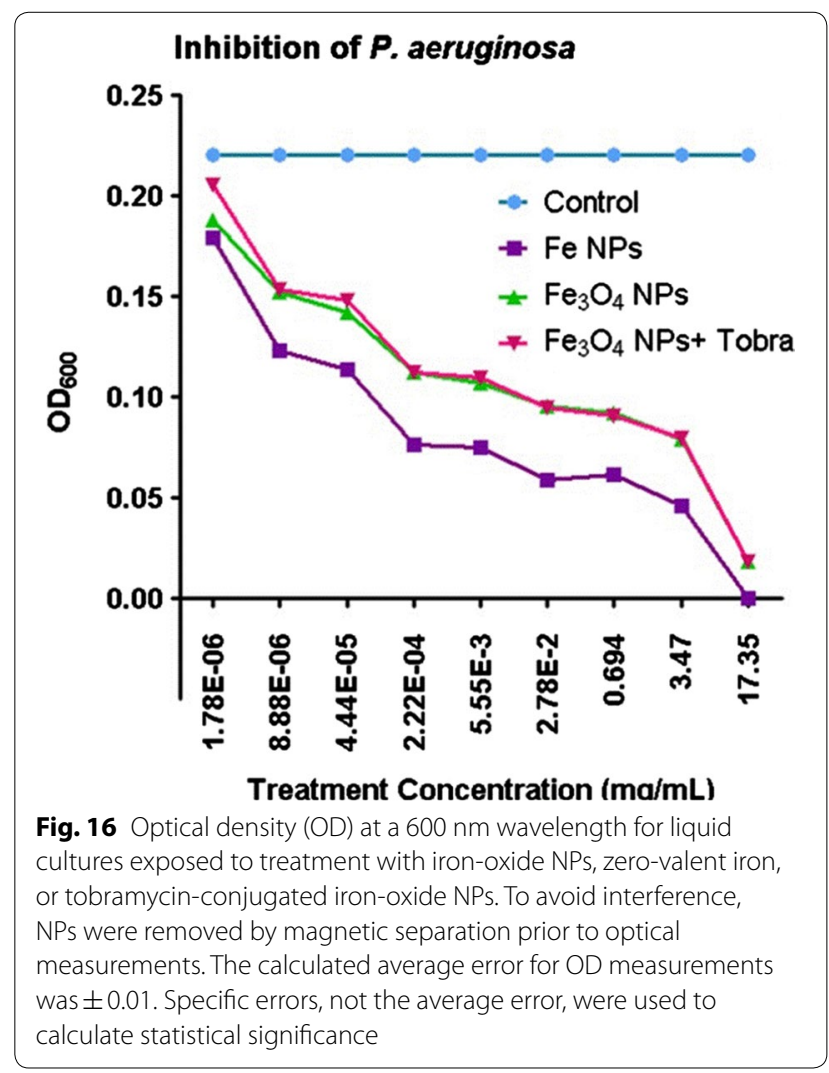


illustrates. Complete inhibition was observed for all materials at concentrations at $17.5 \mathrm{mg} / \mathrm{mL}$ (or higher), and various degrees of inhibition fall off somewhat linearly at concentrations below $17.35 \mathrm{mg} / \mathrm{mL}$ (Fig. 16). The inhibition by zero-valent iron was, not surprisingly, higher than iron-oxide NPs and NP-drug conjugates. We attribute this to the high reactivity of zero-valent iron and its ability to increase reactive oxygen species (ROS) in the local region [182]. Although speculative at this stage, it is also possible that high levels of iron contribute to cellular toxicity. More work is necessary to determine toxic and non-toxic dose ranges.

ANOVA results showed that, while there was no statistically significant difference between the zero-valent iron, iron oxide, or iron-oxide-tobramycin conjugates; when compared to control, the results for all three NP treatments were found to be extremely statistically significant $(p<0.0001)$. Figure 17 shows that the inhibition of bacterial cells was evident even at surprisingly low $(8 \mathrm{ng} / \mathrm{mL})$ concentrations, although the minimum therapeutic dose would probably be much higher; the range in which more significant bacterial inhibition was observed. Speculation on a therapeutic dose for targeted delivery would likely differ from the systemic dose, and both will depend on observed cytotoxicity in mammalian cell cultures, at these concentrations. Even higher doses may be required for the treatment of chronic infections involving biofilms that have been established for several years; however, more research is necessary to determine this.

These findings attest to the feasibility using these materials as antimicrobial coatings or therapeutic agents. The MIC for different strains of $P$. aeruginosa may differ as well. According to another report, $P$. aeruginosa (MTTC 1034) was not found to be susceptible to iron-oxide NPs at $50 \mathrm{mg} / \mathrm{mL}$, whereas our strain exhibited positive susceptibility [120]. It has been shown previously that oxygen limitation and metabolic activity can alter MIC of tobramycin in $P$. aeruginosa [183]. Differences in zone diameter for susceptibility testing have also been known to differ with different batches of growth agar [184]. [118] reported positive bacterial inhibition for $P$. aeruginosa PAO1, in agreement with our findings. We attribute differences in susceptibilities to genetic differences among strains in combination with the contribution of environmental factors, such as growth media and the use of different capping agents.

The mechanism by which iron-oxide NPs exhibit antibacterial activity remains unknown. However, according

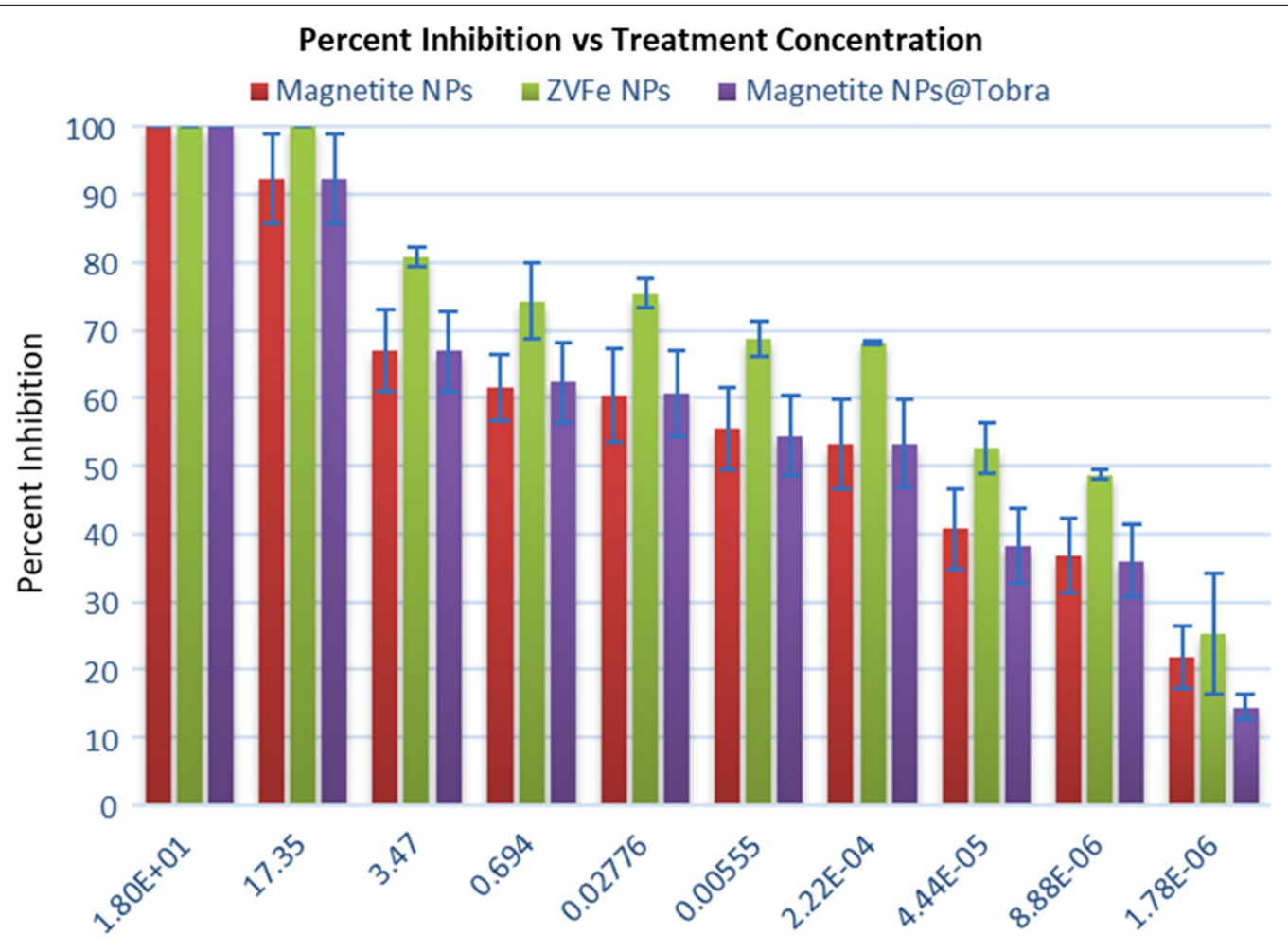

Treatment Concentration $(\mathrm{mg} / \mathrm{mL})$

Fig. 17 Percent bacterial inhibition vs. treatment concentration in liquid cultures in cuvette. All NP samples presented here were capped with alginate 
to the findings of [185], iron may very well be the bioactive component. Zero-valent iron, as predicted, had a dramatic antibacterial effect, verifying the findings of [186]. Although zero-valent iron is too reactive for in vivo use at present, it may be a candidate for incorporation into antibacterial coatings. Similarly, iron-oxide NPs having high biocompatibility, may be a candidate material for incorporation into polymer for use as antibacterial coatings on virtually any inert surface used outside of the body, as well as medical devices such as stents, catheters, and surgical sutures as a low-cost alternative to silver NPs. We anticipate that the combination of tobramycin or other drugs with iron-oxide NPs incorporated into biodegradable polymers may hold promise for the long-term control of biofilms and multidrug resistant microbial strains. More work is needed to determine antibacterial properties of these materials on other microbial species.

\section{Discussion}

Although we have demonstrated the antibacterial properties of NP-drug conjugates or NPs alone, it is not yet known if the NPs or NP-drug conjugates cross the bacterial cell membrane, or if action uptake by the cell is not necessary for the antibacterial effect. It has been shown that aminoglycoside antibiotics, such as tobramycin, enter the cell through porin channels, as altered permeability of the cellular membrane is known to lead to antibiotic resistance [187-189]. P. aeruginosa has previously been shown to possess a relatively large exclusion limit having a $\sim 3 \mathrm{kDa}$ cutoff [190].

The exact mechanism of the antimicrobial action of $\mathrm{Fe}_{3} \mathrm{O}_{4}$ NPs that results in damaging the bacterial proteins and DNA has not yet been determined, but it has been hypothesized that it might involve oxidative stress caused by reactive oxygen species, such as superoxide radicals $\left(\mathrm{O}_{2}^{-}\right)$, singlet oxygen $\left({ }^{1} \mathrm{O}_{2}\right)$, hydroxyl radicals $(-\mathrm{OH})$, or hydrogen peroxide $\left(\mathrm{H}_{2} \mathrm{O}_{2}\right)$ [191]. For example, $\mathrm{H}_{2} \mathrm{O}_{2}$ could penetrate the cell membrane of the bacteria and kill the bacteria by entering the intracellular space. It appears that a destructive consequence appears under of greater concentrations of zero-valent iron and consequently, ROS induced by the presence of iron. Experimentation to determine the bactericidal effects of zero-valent iron and the theoretical mechanisms leading to cell death has been done previously, and the established findings may be referenced in any of the following notable publications. The first of which reports significant disruption of the Escherichia coli cell membrane by zero-valent iron NPs suggesting inactivation or enhanced the biocidal effects of dissolved iron as well as oxidative stress as mechanisms of cell death [192]. Another report, [193], investigated the use of zero-valent iron NPs against
Gram negative Escherichia coli and Gram-positive Bacillus subtilis showing that B. subtilis was more tolerant to zero-valent iron NPs than E. coli, but states that the bactericidal mechanism has not yet been elucidated. Despite these findings, there is not yet a consensus in the literature regarding this effect; another paper published elsewhere claims that zero-valent iron had no deleterious effect on total bacterial abundance in the microcosms. This paper reports that zero-valent iron with a biodegradable polyaspartate cap increased bacterial populations by an order of magnitude relative to controls [194]. Perhaps, upon reaching stable oxidation equilibrium in the body, this material will benefit bacterial populations by providing beneficial doses of iron.

It is possible that iron NPs may indirectly generate ROS, which subsequently damage iron-sulfur clusters located in an assortment of metalloproteins, examples are the well-known nicotinamide adenine dinucleotide (NADH) dehydrogenase, ferredoxins, hydrogenases, nitrogenase, coenzyme Q, and succinate dehydrogenase [195]. The combination of radicals and aqueous iron produces Fenton's reagent. Fenton's reagent is a solution of hydrogen peroxide and iron. In industrial applications, Fenton's reagent can be used to destroy organic compounds by catalyzing the production of additional ROS. ROS generated by this reaction can easily diffuse into the cell cytoplasm, triggering ROS-induced release in the mitochondria triggering death.

Another way that the Fenton's reagent mechanism may be applicable to the antibacterial effects of iron oxide is free-radical DNA damage. The superoxide anion $\left(\mathrm{O}_{2}^{--}\right)$ can dismutate to form hydrogen peroxide $\mathrm{H}_{2} \mathrm{O}_{2}$ [196]. $\mathrm{O}_{2}^{--}$can also reduce $\mathrm{Fe}(\mathrm{III})$, thus releasing it from the ferritin protein according to:

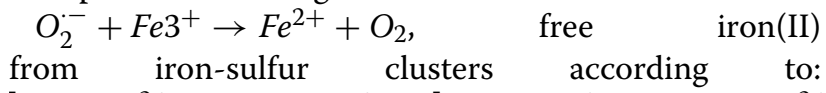
$[4 \mathrm{Fe}-\mathrm{S}]^{2+}+\mathrm{O}_{2}^{--}+2 \mathrm{H}^{+} \rightarrow\left[3 \mathrm{Fe}-4 \mathrm{~S}^{+}+\mathrm{H}_{2} \mathrm{O}_{2}+\mathrm{Fe}^{2+}\right.$, and subsequently, very reactive oxygen species can form through the Fenton reaction $\mathrm{Fe}^{2+}+\mathrm{H}^{+}+\mathrm{H}_{2} \mathrm{O}_{2} \rightarrow \mathrm{Fe}^{3+}+\cdot \mathrm{OH}+\mathrm{H}_{2} \mathrm{O}_{2}$.

The Fenton reaction has been linked to DNA damage by its products: iron, $\mathrm{O}_{2}$, and $\mathrm{H}_{2} \mathrm{O}_{2}$ [196]. $\mathrm{Fe}^{3+}$ produced by the Fenton reaction is thought to be reduced by available $\mathrm{NADH}$, thus replenishing $\mathrm{Fe}^{2+}, \mathrm{H}_{2} \mathrm{O}_{2}$ can be depleted by catalase or by peroxidases, which utilize reduced glutathione, other thiols, cytochrome $c$, and ascorbate [196]. Mechanisms of bacterial cell death induced by the Fenton reaction are illustrated in Fig. 18.

It may also be possible that initial disruption of the outside membrane of bacteria by tobramycin assists the subsequent penetration of NP-tobramycin complexes and or iron ions into the bacterial cell via simple diffusion since it is known that one mechanism of action of 


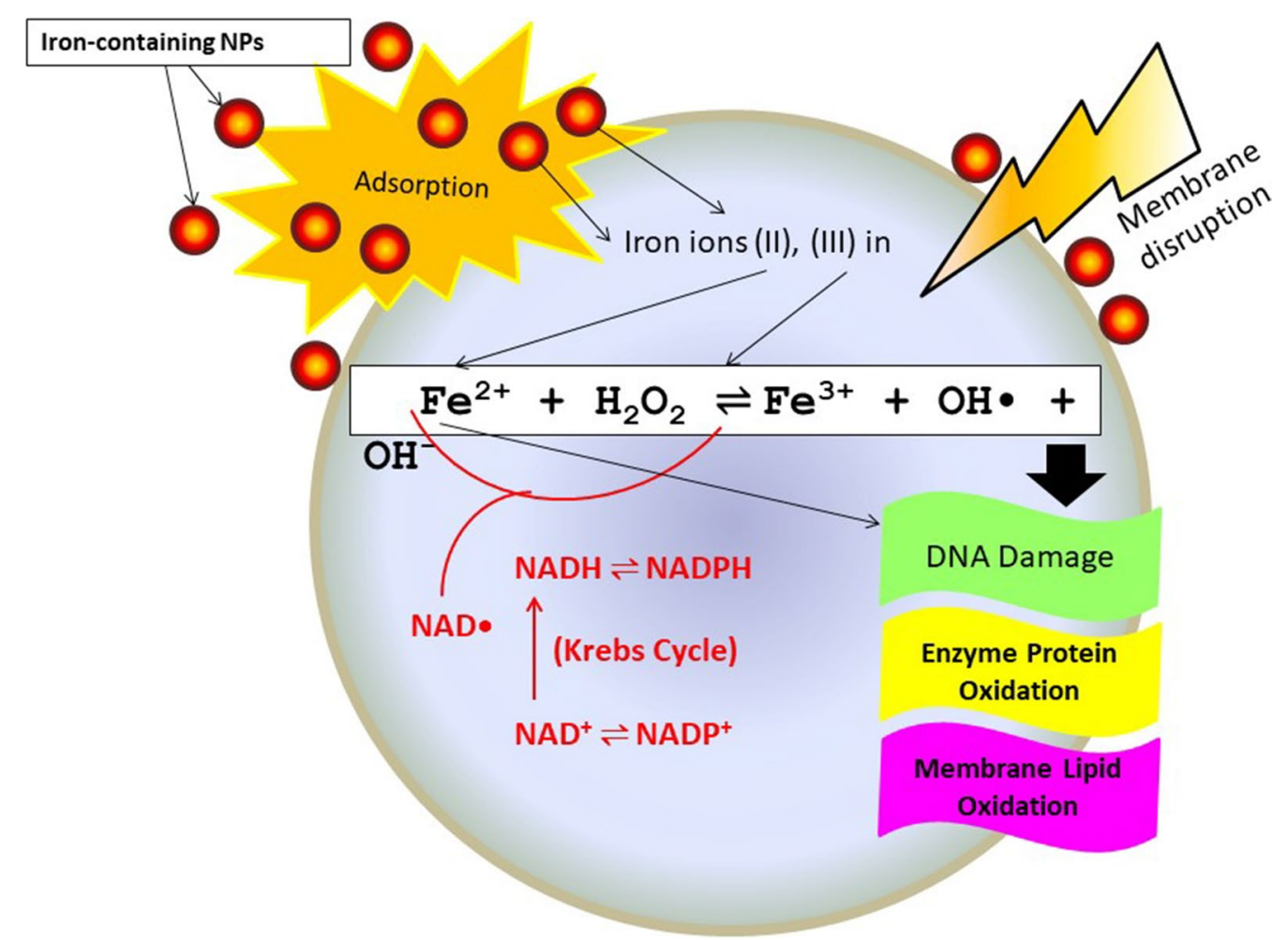

Fig. 18 Mechanisms of cell damage and response after exposure to iron-containing NPs. Iron ions, released from NPs, can cross the membrane via either active cellular uptake or leakage through sites with reduced membrane integrity. Highly reactive hydroxyl radicals resulting from Fe ${ }^{2+}$ reaction with hydrogen peroxide primarily cause oxidative damage. $\mathrm{Fe}^{3+}$ could be reduced by NADH and, thus, regenerating Fe ${ }^{2+}$. OH.radicals could also cause damage to DNA, proteins and lipids. $\mathrm{Fe}^{2+}$ may also directly damage DNA

aminoglycoside antibiotics is interference with protein synthesis leading to cell membrane disruption. However, if this is occurring, it is not happening on a large scale since no statistically significant difference in the MIC or susceptibility was noted in tobramycin conjugated iron-oxide NPs compared to unconjugated NPs. However, more work is needed to clarify the antibacterial mechanism(s) of action of iron-oxide NPs alone and in combination with the aminoglycoside, or other antibiotic drugs, and to clarify the overall role of the capping agent.

It is apparent that the composition of the capping agent, and possibly the interactions of the capping agent with the NP surface, the ROS, and the cell surfaces are primarily responsible for facilitating or negating the antimicrobial effects. Since uncapped iron-oxide NPs $(\sim 16 \mathrm{~nm})$ had similar antibacterial effects as the alginatecapped and alginate-capped/tobramycin conjugated NPs $(\sim 200 \mathrm{~nm})$, whereas the PEG-capped NPs $(\sim 40 \mathrm{~nm})$ were ineffective, we do not attribute these findings to size effects. At least at this size range.

\section{Conclusions}

We report the susceptibility and inhibitory concentrations of iron-oxide (nominally magnetite) nanoparticles (NPs) with and without attached drug (tobramycin) against $P$. aeruginosa PAO1 communities. The NPs investigated in this study have an average hydrodynamic diameter of $16 \mathrm{~nm}$, prior to capping with natural alginate. The NP-drug conjugates were prepared using 1-ethyl-3-(3dimethylaminopropyl)carbodiimide hydrochloride/Nhydroxysulfosuccinimide (EDC/sulfo-NHS) crosslinking of the aminoglycoside antibiotic tobramycin with alginate, by way of carboxyl and amine functional groups. Bacterial biofilm cultures were grown for 60 days to more closely model an established infection. We also investigated an in vitro CF model, in which a magnetic gradient was applied to NP-drug conjugates atop an artificial biofilm (alginate layer) and mucus layer on agar. Positive inhibition of bacterial growth was observed for uncapped and alginate-capped iron-oxide NPs, and the corresponding MICs have been presented. We have observed zero susceptibility to iron-oxide NPs capped with PEG, suggesting that the capping agent plays a major role in enabling bactericidal ability in of the nanocomposite. Our 
findings suggest that the alginate-coated nanocomposites investigated in this study have the potential to overcome the bacterial biofilm barrier, possibly by simple diffusion, due to the favorable solubility of the alginate-coated NPs within the alginate biofilm. Magnetic field application increases the action, likely via enhanced diffusion of the iron-oxide NPs and NP-drug conjugates through mucin and alginate barriers, which are characteristic of $\mathrm{CF}$ respiratory infections. We have demonstrated that ironoxide NPs coated with alginate, as well as alginate-coated magnetite-tobramycin conjugates inhibit $P$. aeruginosa growth and biofilm formation in established colonies, which are often the most difficult to treat. We have also determined that susceptibility to tobramycin decreases for longer culture times, as the colonies are allowed to differentiate for longer periods of time. In contrast, susceptibility to the iron-oxide NP compounds did not demonstrate any comparable decrease with increasing culture time. These findings appear to imply that iron-oxide NPs are promising lower-cost alternatives to silver NPs in antibacterial coatings, solutions, and drugs, as well as other applications in which microbial abolition or infestation prevention is sought. Future work should include multiple strains of $P$. aeruginosa in order to determine to what extend the response may be strain-dependent, as well as detailed investigations into the mechanism(s) of action.

\begin{abstract}
Abbreviations
NP: Nanoparticle; CF: Cystic fibrosis; MDR: Multidrug resistant; ICU: Intensive care unit; VAP: Ventilator-associated pneumonia; EPS: Extracellular polysaccharide; M: Mannuronic acid; G: Guluronic acid; PEG: Polyethylene glycol; EDC: 1-ethyl-3-(3-dimethylaminopropyl)carbodiimide; TEM: Transmission electron microscopy; DLS: Dynamic light scattering; XRD: X-ray diffraction; EDS: Energydispersive X-ray spectroscopy; MIC: Minimum inhibitory concentration; DI: Deionized; mPEG: Methyl-terminated PEG; NHS: N-hydroxysuccinimide; FTIR: Fourier-transform infrared; HRTEM: High-resolution TEM; MPMS: Magnetic property measurement system; SQUID: Superconducting quantum interference device; ZFC: Zero-field cooling; FC: Field cooling; UV-VIS-IR: Ultravioletvisible-infrared; OD: Optical density; LB: Luria-Bertani; CFU: Colony forming unit; ZOI: Zone of inhibition; CLSI: Clinical and Laboratory Standards Institute; ROS: Reactive oxygen species; NADH: Nicotinamide adenine dinucleotide.
\end{abstract}

\begin{abstract}
Acknowledgements
This work was performed, in part, at the Center for Integrated Nanotechnologies, an Office of Science User Facility operated for the U.S. Department of Energy (DOE) Office of Science by Los Alamos National Laboratory (Contract DE-AC52-06NA25396) and Sandia National Laboratories (Contract DE-NA0003525), under the Project \#C2015A0105 "Characterization of Superparamagnetic Nanoparticles for Enhanced Drug Delivery to the Lung". Sandia National Laboratories is a multimission laboratory managed and operated by National Technology \& Engineering Soultions of Sandia, LLC, a wholly owned subsidiary of Honeywell International, Inc., for the U.S. DOE's National Nuclear Security Administration under contract DE-NA-0003525. The views expressed in the article do not necessarily represent the views of the U.S. DOE or the United States Government.
\end{abstract}

\section{Authors' contributions}

LMA performed the design of the experiments. SJW and MK contributed to the synthesis of NPs under the supervision of LMA. MK assisted with the drug conjugation procedure under the supervision of $L M A$ and $Y I B$. ACR and NCC performed the TEM and EDS analyses. DLH and TCM performed magnetic characterization. LMA performed the XRD and DLS analyses. LMA, YIB and NJW performed the cell culture experiments. The manuscript was written by LMA and MO. HDCS and MO contributed with crucial discussions and constructive reviews. All authors read and approved the final manuscript.

\section{Funding}

This work was supported in part by the National Institutes of Health $(\mathrm{NIH})$ under the Grant No. 1R21HL092812-01A1 "Multifunctional Nanoparticles: Nano-Knives and Nano-Pullies for Enhanced Drug Delivery to the Lung". Leisha M. Armijo was supported in part by the NIH under the Grant No. GM-060201 Initiatives to Maximize Student Diversity (IMSD); the NSF IGERT program on "Integrating Nanotechnology with Cell Biology and Neuroscience", Grant No. DGE-0549500; and by the More Graduate Education @ Mountain States Alliance (MGE@MSA) program through Arizona State University.

Availability of data and materials

All data generated or analyzed, and materials used in this study are included in this manuscript.

\section{Ethics approval and consent to participate}

No animals, human participants, human data, or human tissues were used in this study.

\section{Consent for publication}

Not applicable.

\section{Competing interests}

The authors declare that they have no competing interests.

\section{Author details}

${ }^{1}$ Center for High Technology Materials, University of New Mexico, 1313 Goddard Street SE, Albuquerque, NM 87106-4343, USA. ${ }^{2}$ Center for Integrated Nanotechnologies, Sandia National Laboratories, 1000 Eubank SE, Albuquerque, NM 87123, USA. ${ }^{3}$ Sandia National Laboratories, Nanomaterials Sciences, P.O. Box 5800, MS 1415, Albuquerque, NM 87185, USA. ${ }^{4}$ College of Pharmacy, The University of Texas at Austin, 2409 University Avenue, Stop A1900, Austin, TX 78712, USA.

Received: 6 March 2019 Accepted: 29 January 2020

Published online: 18 February 2020

\section{References}

1. Tan SY, Tatsumura Y. Alexander Fleming (1881-1955): discoverer of penicillin. Singapore Med J. 2015;56(7):366-7.

2. Rice LB. Federal funding for the study of antimicrobial resistance in nosocomial pathogens: no ESKAPE. J Infect Dis. 2008;197(8):1079-81.

3. Boucher HW, Talbot GH, Bradley JS, Edwards JE, Gilbert D, Rice LB, Scheld M, Spellberg B, Bartlett J. Bad bugs, no drugs: no ESKAPE! An update from the Infectious Diseases Society of America. Clin Infect Dis. 2009;48(1):1-12.

4. Bradford PA, Bratu S, Urban C, Visalli M, Mariano N, Landman D, Rahal JJ, Brooks S, Cebular S, Quale J. Emergence of carbapenem-resistant Klebsiella species possessing the class A carbapenem-hydrolyzing KPC-2 and inhibitor-resistant TEM-30 $\beta$-lactamases in New York City. Clin Infect Dis. 2004;39(1):55-60.

5. Cardo D, Horan T, Andrus M, Dembinski M, Edwards J, Peavy G, Tolson J, Wagner D. National Nosocomial Infections Surveillance (NNIS) System Report, data summary from January 1992 through June 2004, issued October 2004. Am J Infect Control. 2004;32(8):470-85.

6. Falagas ME, Kasiakou SK, Saravolatz LD. Colistin: the revival of polymyxins for the management of multidrug-resistant gram-negative bacterial infections. Clin Infect Dis. 2005;40(9):1333-41.

7. Falagas ME, Bliziotis IA. Pandrug-resistant Gram-negative bacteria: the dawn of the post-antibiotic era? Int J Antimicrob Agents. 2007;29(6):630-6.

8. Urban C, Bradford PA, Tuckman M, Segal-Maurer S, Wehbeh W, Grenner L, Colon-Urban R, Mariano N, Rahal JJ. Carbapenem-resistant 
Escherichia coli harboring Klebsiella pneumoniae carbapenemase $\beta$-lactamases associated with long-term care facilities. Clin Infect Dis. 2008;46(11):e127-30.

9. Williams KP, Gillespie JJ, Sobral BWS, Nordberg EK, Snyder EE, Shallom JM, Dickerman AW. Phylogeny of Gammaproteobacteria. J Bacteriol. 2010;192(9):2305-14.

10. Streeter K, Katouli M. Pseudomonas aeruginosa: a review of their pathogenesis and prevalence in clinical settings and the environment. Infect Epidemiol Med. 2016;2(1):25-32.

11. Hirsch EB, Tam VH. Impact of multidrug-resistant Pseudomonas aeruginosa infection on patient outcomes. Exp Rev Pharmacoecon Outcomes Res. 2010;10(4):441-51.

12. Nathwani D, Raman G, Sulham K, Gavaghan M, Menon V. Clinical and economic consequences of hospital-acquired resistant and multidrugresistant Pseudomonas aeruginosa infections: a systematic review and meta-analysis. Antimicrob Res Infect Control. 2014;20(3):32.

13. Global priority list of antibiotic-resistant bacteria to guide research, discovery, and development of new antibiotics. World Health Organization Report. 2017;1-7.http://www.who.int/medicines/publications/ WHO-PPL-Short_Summary_25Feb-ET_NM_WHO.pdf?ua=1. Accessed 10 Jul 2017.

14. Pseudomonas aeruginosa in healthcare settings. Center for Disease Control. https://www.cdc.gov/hai/organisms/pseudomonas.html. Accessed 31 May 2017.

15. Fick RBJ. Pseudomonas aeruginosa the opportunist: pathogenesis and disease. Boca Raton: CRC Press; 1992.

16. Obritsch MD, Fish DN, MacLaren R, Jung R. Nosocomial infections due to multidrug-resistant Pseudomonas aeruginosa: epidemiology and treatment options. Pharmacotherapy. 2005;25(10):1353-64.

17. Shaikh S, Fatima J, Shakil S, Rizvi SMD, Kamal MA. Prevalence of multidrug resistant and extended spectrum beta-lactamase producing Pseudomonas aeruginosa in a tertiary care hospital. Saudi J Biol Sci. 2015;22(1):62-4.

18. Khan HA, Ahmad A, Mehboob R. Nosocomial infections and their control strategies. Asian Pac J Trop Biomed. 2015;5(7):509-14.

19. Gilligan PH. Microbiology of airway disease in patients with cystic fibrosis. Clin Microbiol Rev. 1991;4(1):35-51.

20. Hsueh P-R, Teng L-J, Yang P-C, Chen Y-C, Ho S-W, Luh K-T. Persistence of a multidrug-resistant Pseudomonas aeruginosa clone in an intensive care burn unit. J Clin Microbiol. 1998;36(5):1347-51.

21. Bhatt P, Rathi KR, Hazra S, Sharma A, Shete V. Prevalence of multidrug resistant Pseudomonas aeruginosa infection in burn patients at a tertiary care centre. Indian J Burns. 2015;23(1):56-9.

22. Raineri E, Porcella L, Acquarolo A, Crema L, Albertario F, Candiani A. Ventilator-associated pneumonia caused by Pseudomonas aeruginosa in intensive care unit: epidemiology and risk factors. J Med Microbiol Diagn. 2014;3(3):149-55.

23. Gill JS, Arora S, Khanna SP, Hari Kumar KVS. Prevalence of multidrugresistant, extensively drug-resistant, and pandrug-resistant Pseudomonas aeruginosa from a tertiary level intensive care unit. J Glob Infect Dis. 2016;8(4):155-9.

24. Garvey MI, Bradley CW, Tracey J, Oppenheim B. Continued transmission of Pseudomonas aeruginosa from a wash hand basin tap in a critical care unit. J Hosp Infect. 2016;94(1):8-12.

25. Neuhauser MM, Weinstein RA, Rydman R, Danziger LH, Karam G, Quinn JP. Antibiotic resistance among gram-negative bacilli in US intensive care units: implications for fluoroquinolone use. JAMA. 2003;289(7):885-8.

26. Fujitani S, Sun HY, Yu VL, Weingarten JA. Pneumonia due to Pseudomonas aeruginosa: part I: epidemiology, clinical diagnosis, and source. Chest. 2011;139(4):909-19.

27. Bouglé A, Foucrier A, Dupont H, Montravers P, Ouattara A, Kalfon $P_{\text {, }}$ Squara P, Simon T, Amour J. Impact of the duration of antibiotics on clinical events in patients with Pseudomonas aeruginosa ventilator-associated pneumonia: study protocol for a randomized controlled study. Trials. 2017;18(1):37.

28. Brewer SC, Wunderink RG, Jones CB, Leeper KV. Ventilatorassociated pneumonia due to Pseudomonas aeruginosa. Chest. 1996;109(4):1019-29.

29. Trouillet JL, Vuagnat A, Combes AA, Kassis N, Chastre J, Gibert C. Pseudomonas aeruginosa ventilator-associated pneumonia: comparison of episodes due to piperacillin-resistant versus piperacillin-susceptible organisms. Clin Infect Dis. 2002;34(8):1047-54.

30. Garnacho-Montero J, Sa-Borges M, Sole-Violan J, Barcenilla F, EscorescaOrtega A, Ochoa M, Cayuela A, Rello J. Optimal management therapy for Pseudomonas aeruginosa ventilator-associated pneumonia: an observational, multicenter study comparing monotherapy with combination antibiotic therapy. Crit Care Med. 2007;35(8):1888-95.

31. Planquette B, Timsit JF, Misset BY, Schwebel C, Azoulay E, Adrie C, Vesin A, Jamali S, Zahar JR, Allaouchiche B, Souweine B. Pseudomonas aeruginosa ventilator-associated pneumonia predictive factors of treatment failure. Am J Respir Crit Care Med. 2013;188(1):69-76.

32. Thaden JT, Park LP, Maskarinec SA, Ruffin F, Fowler VG Jr, van Duin D. Results from a 13-year prospective cohort study show increased mortality associated with bloodstream infections caused by Pseudonomas aeruginosa compared to other bacteria. Antimicrob Agents Chemother. 2017;61(6):e02671.

33. Gellatly SL, Hancock REW. Pseudomonas aeruginosa: new insights into pathogenesis and host defenses. Pathogens and Disease. 2013;67(3):159-73.

34. Costerton JW, Stewart PS, Greenberg EP. Bacterial biofilms: a common cause of persistent infections. Science. 1999;284(5418):1318-22.

35. An D, Parsek MR. The promise and peril of transcriptional profiling in biofilm communities. Curr Opin Microbiol. 2007;10(3):292-6.

36. Davies DG, Geesey GG. Regulation of the alginate biosynthesis gene algC in Pseudomonas aeruginosa during biofilm development in continuous culture. Appl Environ Microbiol. 1995;61(3):860-7.

37. Donlan RM. Biofilms: microbial life on surfaces. Emerg Infect Dis. 2002;8(9):881-90.

38. Linker A, Jones RS. A new polysaccharide resembling alginic acid isolated from pseudomonads. J Biol Chem. 1966;241(16):3845-51.

39. Evans LR, Linker A. Production and characterization of the slime polysaccharide of Pseudomonas aeruginosa. J Bacteriol. 1973;116(2):915-24.

40. Alginates Gacesa P. Carbohyd Polym. 1988;8(3):161-82.

41. Lee KY, Mooney DJ. Alginate: properties and biomedical applications. Prog Polym Sci. 2012;37:106-26.

42. Szekalska M, Puciłowska A, Szymańska A, Ciosek P, Winnicka K. Alginate: current use and future perspectives in pharmaceutical and biomedical applications. Int J Polym Sci. 2016;2016:7697031.

43. Kathju S, Nistico L, Hall-Stoodley L, Post JC, Ehrlich GD, Stoodley P. Chronic surgical site infection due to suture-associated polymicrobial biofilm. Surg Infect. 2009;10(5):457-61.

44. Henry-Stanley MJ, Hess DJ, Barnes AMT, Dunny GM, Wells CL. Bacterial contamination of surgical suture resembles a biofilm. Surg Infect. 2010;11(5):433-9.

45. Hess DJ, Henry-Stanley MJ, Wells CL. Gentamicin promotes Staphylococcus aureus biofilms on silk suture. J Surg Res. 2011;170(2):302-8.

46. Chun M-J, Shim EJ, Kho E-H, Park K-J, Jung J, Kim J-M, Kim BH, Lee K-H, Cho D-L, Bai D-H, Lee S-I, Hwang H-S, Ohk S-H. Surface modification of orthodontic wires with photocatalytic titanium oxide for its antiadherent and antibacterial properties. Angle Orthod. 2007;77(3):483-8.

47. Lee H-J, Park H-S, Kim K-H, Kwon T-Y, Hong S-H. Effect of garlic on bacterial biofilm formation on orthodontic wire. Angle Orthod. 2011:81(5):895-900.

48. Trautner BW, Darouiche RO. Role of biofilm in catheter-associated urinary tract infection. Am J Infect Control. 2004;32(3):177-83.

49. Stickler DJ. Bacterial biofilms in patients with indwelling urinary catheters, Nature Clinical Practice. Urology. 2008;5(11):598-608.

50. Stickler DJ. Clinical complications of urinary catheters caused by crystalline biofilms: something needs to be done. J Intern Med. 2014;276(2):120-9.

51. Andes D, Nett J, Oschel P, Albrecht R, Marchillo K, Pitula A. Development and characterization of an in vivo central venous catheter Candida albicans biofilm model. Infect Immun. 2004;72(10):6023-31.

52. Raad I, Hanna H, Jiang Y, Dvorak T, Reitzel R, Chaiban G, Sherertz R, Hachem R. Comparative activities of daptomycin, linezolid, and tigecycline against catheter-related methicillin-resistant Staphylococcus bacteremic isolates embedded in biofilm. Antimicrob Agents Chemother. 2007;51(5):1656-60.

53. Choong $\mathrm{S}$, Whitfield $\mathrm{H}$. Biofilms and their role in infections in urology. BJU International. 2000;86(8):935-41. 
54. Laube N, Kleinen L, Bradenahl J, Meissner A. Diamond-like carbon coatings on ureteral stents-a new strategy for decreasing the formation of crystalline bacterial biofilms? J Urol. 2007;177(5):1923-7.

55. Perloff JR, Palmer JN. Evidence of bacterial biofilms on frontal recess stents in patients with chronic rhinosinusitis. Am J Rhinol. 2004;18(6):377-80.

56. Donelli G, Guaglianone E, Di Rosa R, Fiocca F, Basoli A. Plastic biliary stent occlusion: factors involved and possible preventive approaches. Clin Med Res. 2007:5(1):53-60.

57. Bauer TT, Torres A, Ferrer R, Heyer CM, Schultze-Werninghaus C, Rasche K. Biofilm formation in endotracheal tubes. Association between pneumonia and the persistence of pathogens. Monaldi Arch Chest Dis. 2002;57(1):84-7.

58. Danin P-E, Girou E, Legrand P, Louis B, Fodil R, Christov C, Devaquet $J$, Isabey D, Brochard L. Description and microbiology of endotracheal tube biofilm in mechanically ventilated subjects. Resp Care. 2015;60(1):21-9.

59. Donlan RM, Costerton JW. Biofilms: survival mechanisms of clinically relevant microorganisms. Clin Microbiol Rev. 2002;15(2):167-93.

60. Govan JR, Deretic V. Microbial pathogenesis in cystic fibrosis: mucoid Pseudomonas aeruginosa and Burkholderia cepacia. Microbiol Rev. 1996;60(3):539-74.

61. Sondi I, Salopek-Sondi B. Silver nanoparticles as antimicrobial agent: a case study on E. coli as a model for Gram-negative bacteria. J Colloid Interface Sci. 2004;275(1):177-82.

62. Morones JR, Elechiguerra JL, Camacho A, Holt K, Kouri JB, Ramírez JT, Yacaman MJ. The bactericidal effect of silver nanoparticles. Nanotechnology. 2005;16(10):2346-53.

63. Cho K-H, Park J-E, Osaka T, Park S-G. The study of antimicrobial activity and preservative effects of nanosilver ingredient. Electrochim Acta. 2005;51(5):956-60.

64. Kim JS, Kuk E, Yu KN, Kim J-H, Park SJ, Lee HJ, Kim SH, Park YK, Park YH, Hwang C-Y, Kim Y-K, Lee Y-S, Jeong DH, Cho M-H. Antimicrobial effects of silver nanoparticles. Nanomedicine. 2007;3(1):95-101.

65. Pal S, Tak YK, Song JM. Does the antibacterial activity of silver nanoparticles depend on the shape of the nanoparticle? A study of the Gram-negative bacterium Escherichia coli. Appl Environ Microbiol. 2007;73(6):1712-20

66. Shrivastava S, Bera T, Roy A, Singh G, Ramachandrarao P, Dash D. Characterization of enhanced antibacterial effects of novel silver nanoparticles. Nanotechnology. 2007;18(22):225103.

67. Durán N, Marcato PD, De Souza GIH, Alves OL, Esposito E. Antibacterial effect of silver nanoparticles produced by fungal process on textile fabrics and their effluent treatment. J Biomed Nanotechnol. 2007;3(2):203-8.

68. Martínez-Castañón GA, Niño-Martínez N, Martínez-Gutierrez F, Martínez-Mendoza JR, Ruiz F. Synthesis and antibacterial activity of silver nanoparticles with different sizes. J Nanopart Res. 2008;10(8):1343-8.

69. Rai M, Yadav A, Gade A. Silver nanoparticles as a new generation of antimicrobials. Biotechnol Adv. 2009;27(1):76-83.

70. Chudasama B, Vala AK, Andhariya N, Mehta RV, Upadhyay RV. Highly bacterial resistant silver nanoparticles: synthesis and antibacterial activities. J Nanopart Res. 2010;12(5):1677-85.

71. Lara HH, Garza-Treviño EN, Ixtepan-Turrent L, Singh DK. Silver nanoparticles are broad-spectrum bactericidal and virucidal compounds. J Nanobiotechnol. 2011;3(9):30.

72. El-Kheshen AA, El-Rab SFG. Effect of reducing and protecting agents on size of silver nanoparticles and their anti-bacterial activity. Der Pharma Chemica. 2012;4(1):53-65.

73. Dong PV, $\mathrm{HaCH}$, Binh LT, Kasbohm J. Chemical synthesis and antibacterial activity of novel-shaped silver nanoparticles. Int Nano Lett. 2012;2(1):9.

74. Prabhu S, Poulose EK. Silver nanoparticles: mechanism of antimicrobial action, synthesis, medical applications, and toxicity effects. International Nano Letters. 2012;2(1):32.

75. Le A-T, Le TT, Nguyen VQ, Tran HH, Dang DA, Tran QH, Vu DL. Powerful colloidal silver nanoparticles for the prevention of gastrointestinal bacterial infections. Adv Nat Sci. 2012;3(4):045007.

76. Sadeghi B, Garmaroudi FS, Hashemi M, Nezhad HR, Nasrollahi A, Ardalan S, Ardalan S. Comparison of the anti-bacterial activity on the nanosilver shapes: nanoparticles, nanorods and nanoplates. Adv Powder Technol. 2012;23(1):22-6.

77. Rai MK, Deshmukh SD, Ingle AP, Gade AK. Silver nanoparticles: the powerful nanoweapon against multidrug-resistant bacteria. J Appl Microbiol. 2012;112(5):841-52.

78. Emeka EE, Ojiefoh OC, Aleruchi C, Hassan LA, Christiana OM, Rebecca M, Dare EO, Temitope AE. Evaluation of antibacterial activities of silver nanoparticles green-synthesized using pineapple leaf (Ananas comosus). Micron. 2014;57:1-5.

79. Losasso C, Belluco S, Cibin V, Zavagnin P, Mičetić I, Gallocchio F, Zanella M, Bregoli L, Biancotto G, Ricci A. Antibacterial activity of silver nanoparticles: sensitivity of different Salmonella serovars. Front Microbiol. 2014;26(5):227.

80. Agnihotri S, Mukherji S, Mukherji S. Size-controlled silver nanoparticles synthesized over the range 5-100 nm using the same protocol and their antibacterial efficacy. RSC Adv. 2014;4(8):3974-83.

81. Franci G, Falanga A, Galdiero S, Palomba L, Rai M, Morelli G, Galdiero M. Silver nanoparticles as potential antibacterial agents. Molecules. 2015;20(5):8856-74.

82. Cavaliere E, De Cesari S, Landini G, Riccobono E, Pallecchi L, Rossolini GM, Gavioli L. Highly bactericidal Ag nanoparticle films obtained by cluster beam deposition. Nanomedicine. 2015;11(6):1417-23.

83. Lara HH, Romero-Urbina DG, Pierce C, Lopez-Ribot JL, Arellano-Jiménez MJ, Jose-Yacaman M. Effect of silver nanoparticles on Candida albicans biofilms: an ultrastructural study. J Nanobiotechnol. 2015;15(13):91.

84. Giessen TW, Silver PA. Converting a natural protein compartment into a nanofactory for the size-constrained synthesis of antimicrobial silver nanoparticles. ACS Synth Biol. 2016;5(12):1497-504.

85. Rusol Al-Bahrani R, Raman J, Lakshmanan H, Hassan AA, Sabaratnam $V$. Green synthesis of silver nanoparticles using tree oyster mushroom Pleurotus ostreatus and its inhibitory activity against pathogenic bacteria. Mater Lett. 2017;1 (186):21-5.

86. Patra JK, Baek K-H. Antibacterial activity and synergistic antibacterial potential of biosynthesized silver nanoparticles against foodborne pathogenic bacteria along with its anticandidal and antioxidant effects. Front Microbiol. 2017;5(8):167.

87. Shaker MA, Shaaban MI. Synthesis of silver nanoparticles with antimicrobial and anti-adherence activities against multidrug-resistant isolates from Acinetobacter baumannii. J Taibah Univ Med Sci. 2017;12(4):291-7.

88. Afreen RV, Ranganath E. Synthesis of monodispersed silver nanoparticles by Rhizopus stolonifer and its antibacterial activity against MDR strains of Pseudomonas aeruginosa from burnt patients. Int J Environ Sci. 2011;1(7):1583-92.

89. Eid M, Araby E. Bactericidal effect of poly(acrylamide/itaconic acid)silver nanoparticles synthesized by gamma irradiation against Pseudomonas aeruginosa. Appl Biochem Biotechnol. 2013;171(2):469-87.

90. Palanisamy NK, Ferina N, Amirulhusni AN, Mohd-Zain Z, Hussaini J, Ping $\sqcup J$, Durairaj R. Antibiofilm properties of chemically synthesized silver nanoparticles found against Pseudomonas aeruginosa. J Nanobiotechnol. 2014;14(12):2.

91. Singh K, Panghal M, Kadyan S, Chaudhary U, Yadav JP. Antibacterial activity of synthesized silver nanoparticles from Tinospora cordifolia against multi drug resistant strains of Pseudomonas aeruginosa isolated from burn patients. J Nanomed Nanotechnol. 2014;5(2):192.

92. Ansari MA, Khan HM, Khan AA, Cameotra SS, Saquib Q, Musarrat J. Gum arabic capped-silver nanoparticles inhibit biofilm formation by multidrug resistant strains of Pseudomonas aeruginosa. J Basic Microbiol. 2014;54(7):688-99.

93. Muhsin TM, Hachim AK. Mycosynthesis and characterization of silver nanoparticles and their activity against some human pathogenic bacteria. World J Microbiol Biotechnol. 2014;30(7):2081-90.

94. Singh K, Panghal M, Kadyan S, Chaudhary U, Yadav JP. Green silver nanoparticles of Phyllanthus amarus as an antibacterial agent against multi drug resistant clinical isolates of Pseudomonas aeruginosa. J Nanobiotechnol. 2014;1 (12):40.

95. Mapara N, Sharma M, Shriram V, Bharadwaj R, Mohite KC, Kumar V. Antimicrobial potentials of Helicteres isora silver nanoparticles against extensively drug-resistant (XDR) clinical isolates of Pseudomonas aeruginosa. Appl Microbiol Biotechnol. 2015;99(24):10655-67. 
96. Raza MA, Kanwal Z, Rauf A, Sabri AN, Riaz S, Naseem S. Size- and shapedependent antibacterial studies of silver nanoparticles synthesized by wet chemical routes. Nanomaterials. 2016;15(6):74.

97. Haghighi Pak Z, Abbaspour H, Karimi N, Fattahi A. Eco-friendly synthesis and antimicrobial activity of silver nanoparticles using Dracocephalum moldavica seed extract. Appl Sci. 2016;6(3):69.

98. Nasiri A, Afsar Gharebagh R, Nojoumi SA, Akbarizadeh M, Harirchi S, Arefnezhad M, Sahraei S, Hesaraki M, Afshari M, Javadian F, Sheykhzade Asadi M, Shahi Z, Sargazi A. Evaluation of the antimicrobial activity of silver nanoparticles on antibiotic-resistant Pseudomonas aeruginosa. Int J Basic Sci Med. 2016;1(1):25-8.

99. Kasithevar M, Periakaruppan P, Muthupandian S, Mohan M. Antibacterial efficacy of silver nanoparticles against multi-drug resistant clinical isolates from post-surgical wound infections. Microb Pathog. 2017;107:327-34.

100. Beer C, Foldbjerg R, Hayashi Y, Sutherland DS, Autrup H. Toxicity of silver nanoparticles-nanoparticle or silver ion? Toxicol Lett. 2012;208(3):286-92.

101. Asharani PV, Wu YL, Gong ZY, Valiyaveettil S. Toxicity of silver nanoparticles in zebrafish models. Nanotechnology. 2008;19(25):255102.

102. Navarro E, Piccapietra F, Wagner B, Marconi F, Kaegi R, Odzak N, Sigg L, Behra R. Toxicity of silver nanoparticles to Chlamydomonas reinhardtii. Environ Sci Technol. 2008;42(23):8959-64.

103. Bilberg K, Døving KB, Beedholm K, Baatrup E. Silver nanoparticles disrupt olfaction in Crucian carp (Carassius carassius) and Eurasian perch (Perca fluviatilis). Aquat Toxicol. 2011;104(1):145-52.

104. Kawata K, Osawa M, Okabe S. In vitro toxicity of silver nanoparticles at noncytotoxic doses to HepG2 human hepatoma cells. Environ Sci Technol. 2009;43(15):6046-51.

105. Foldbjerg R, Dang DA, Autrup H. Cytotoxicity and genotoxicity of silver nanoparticles in the human lung cancer cell line, A549. Arch Toxicol. 2011;85(7):743-50.

106. Samanta B, Yan H, Fischer NO, Shi J, Jerry DJ, Rotello VM. Protein-passivated $\mathrm{Fe}_{3} \mathrm{O}_{4}$ nanoparticles: low toxicity and rapid heating for thermal therapy. J Mater Chem. 2008;18(11):1204-8.

107. Sun C, Du K, Fang C, Bhattarai N, Veiseh O, Kievit F, Stephen Z, Lee D, Ellenbogen RG, Ratner B, Zhang M. PEG-mediated synthesis of highly dispersive multifunctional superparamagnetic nanoparticles: their physicochemical properties and function in vivo. ACS Nano. 2010;4(4):2402-10.

108. Prodan AM, Iconaru SL, Ciobanu CS, Chifiriuc MC, Stoicea M, Predoi D. Iron oxide magnetic nanoparticles: characterization and toxicity evaluation by in vitro and in vivo assays. J Nanomater. 2013;2013:587021.

109. Grottone GT, Loureiro RR, Covre J, Rodrigues EB, Pereira Gomes JÁ. ARPE-19 cell uptake of small and ultrasmall superparamagnetic iron oxide. Curr Eye Res. 2014;39(4):403-10.

110. Provenzano R, Schiller B, Rao M, Coyne D, Brenner L, Pereira BJ. Ferumoxytol as an intravenous iron replacement therapy in hemodialysis patients. Clin J Am Soc Nephrol. 2009;4(2):386-93.

111. Coyne DW. Ferumoxytol for treatment of iron deficiency anemia in patients with chronic kidney disease. Expert Opin Pharmacother. 2009;10(15):2563-8.

112. Lu M, Cohen MH, Rieves D, Pazdur R. FDA report: ferumoxytol for intravenous iron therapy in adult patients with chronic kidney disease. Am J Hematol. 2010;85(5):315-9.

113. Weissleder R, Stark DD, Engelstad BL, Bacon BR, Compton CC, White DL, Jacobs P, Lewis J. Superparamagnetic iron oxide: pharmacokinetics and toxicity. Am J Roentgenol. 1989;152(1):167-73.

114. Tran N, Mir A, Mallik D, Sinha A, Nayar S, Webster TJ. Bactericidal effect of iron oxide nanoparticles on Staphylococcus aureus. Int J Nanomed. 2010;2010(5):277-83.

115. Darwish MSA, Nguyen NHA, Ševců A, Stibor I. Functionalized magnetic nanoparticles and their effect on Escherichia coli and Staphylococcus aureus. J Nanomater. 2015;2015:416012.

116. Shi S-F, Jia J-F, Guo X-K, Zhao Y-P, Chen D-S, Guo Y-Y, Zhang X-L. Reduced Staphylococcus aureus biofilm formation in the presence of chitosan-coated iron oxide nanoparticles. Int J Nanomed. 2016;11:6499-506.

117. Chatterjee S, Bandyopadhyay A, Sarkar K. Effect of iron oxide and gold nanoparticles on bacterial growth leading towards biological application. J Nanobiotechnol. 2011;23(9):34.
118. Niemirowicz K, Surel U, Wilczewska AZ, Mystkowska J, Piktel E, Gu X, Namiot Z, Kułakowska A, Savage PB, Bucki R. Bactericidal activity and biocompatibility of ceragenin-coated magnetic nanoparticles. Journal of Nanobiotechnology. 2015;13(1):32.

119. Javanbakht T, Laurent S, Stanicki D, Wilkinson KJ. Relating the surface properties of superparamagnetic iron oxide nanoparticles (SPIONs) to their bactericidal effect towards a biofilm of Streptococcus mutans. PLoS ONE. 2016;11(4):e0154445.

120. Behera SS, Patra JK, Pramanik K, Panda N, Thatoi H. Characterization and evaluation of antibacterial activities of chemically synthesized iron oxide nanoparticles. World J Nano Sci Eng. 2012;2(4):196-200.

121. Prodan AM, Iconaru SL, Chifiriuc CM, Bleotu C, Ciobanu CS, MotelicaHeino M, Sizaret S, Predoi D. Magnetic properties and biological activity evaluation of iron oxide nanoparticles. J Nanomater. 2013;2013:893970.

122. Thukkaram M, Sitaram S, Kannaiyan SK, Subbiahdoss G. Antibacterial efficacy of iron-oxide nanoparticles against biofilms on different biomaterial surfaces. Int J Biomater. 2014;2014:716080.

123. Prabhu YT, Rao KV, Kumari BS, Kumar VSS, Pavani T. Synthesis of $\mathrm{Fe}_{3} \mathrm{O}_{4}$ nanoparticles and its antibacterial application. Int Nano Lett. 2015;5:85-92

124. Arakha M, Pal S, Samantarrai D, Panigrahi TK, Mallick BC, Pramanik K, Mallick B, Jha S. Antimicrobial activity of iron oxide nanoparticle upon modulation of nanoparticle-bacteria interface. Sci Rep. 2015;6(5):14813.

125. Nehra P, Chauhan RP, Garg N, Verma K. Antibacterial and antifungal activity of chitosan coated iron oxide nanoparticles. Br J Biomed Sci. 2018;75:1.

126. Narain R, Gonzales M, Hoffman AS, Stayton PS, Krishnan KM. Synthesis of monodisperse biotinylated p(NIPAAm)-coated iron oxide magnetic nanoparticles and their bioconjugation to streptavidin. Langmuir. 2007;23(11):6299-304.

127. Reddy PM, Chang K-C, Liu Z-J, Chen C-T, Ho Y-P. Evaluation of functionalized magnetic iron oxide $\left(\mathrm{Fe}_{3} \mathrm{O}_{4}\right)$ nanoparticles for capturing Gram-positive and Gram-negative bacteria. J Biomed Nanotechnol. 2014;10(8):1429-39.

128. Sakulkhu U, Mahmoudi M, Maurizi L, Coullerez G, Hofmann-Amtenbrink M, Vries M, Motazacker M, Rezaee F, Hofmann H. Significance of surface charge and shell material of superparamagnetic iron oxide nanoparticle (SPION) based core/shell nanoparticles on the composition of the protein corona. Biomater Sci. 2015;3(2):265-78.

129. Zhu H, Srivastava R, McShane MJ. Spontaneous loading of positively charged macromolecules into alginate-templated polyelectrolyte multilayer microcapsules. Biomacromology. 2005;6(4):2221-8.

130. Shawar RM, MacLeod DL, Garber RL, Burns JL, Stapp JR, Clausen CR, Tanaka SK. Activities of tobramycin and six other antibiotics against Pseudomonas aeruginosa isolates from patients with cystic fibrosis. Antimicrob Agents Chemother. 1999;43(12):2877-80.

131. Banerjee D, Stableforth D. The treatment of respiratory pseudomonas infection in cystic fibrosis: what drug and which way? Drugs. 2000;60(5):1053-64.

132. Whitehead A, Conway SP, Etherington C, Caldwell NA, Setchfield N, Bogle S. Once-daily tobramycin in the treatment of adult patients with cystic fibrosis. Eur Respir J. 2002;9:303-9.

133. Cunha BA. Pseudomonas aeruginosa: resistance and therapy. Semin Respir Infect. 2002;17(3):231-9.

134. Conway SP, Brownlee KG, Denton M, Peckham DG. Antibiotic treatment of multidrug-resistant organisms in cystic fibrosis. Am J Respir Med. 2003;2(4):321-32.

135. Khalil H, Chen T, Riffon R, Wang R, Wang Z. Synergy between polyethylenimine and different families of antibiotics against a resistant clinical isolate of Pseudomonas aeruginosa. Antimicrob Agents Chemother. 2008;52(5):1635-41.

136. Kanj SS, Kanafani ZA. Current concepts in antimicrobial therapy against resistant Gram-negative organisms: extended-spectrum $\beta$-lactamaseproducing Enterobacteriaceae, carbapenem-resistant Enterobacteriaceae, and multidrug-resistant Pseudomonas aeruginosa. Mayo Clin Proc. 2011;86(3):250-9.

137. Sriramulu D. Evolution and impact of bacterial drug resistance in the context of cystic fibrosis disease and nosocomial settings. Microbiol Insights. 2013;14(6):29-36. 
138. McKeage K. Tobramycin inhalation powder: a review of its use in the treatment of chronic infection in patients with cystic fibrosis. Drugs. 2013;73(16):1815-27.

139. Lam J, Vaughan S, Parkins MD. Tobramycin inhalation powder (TIP): an efficient treatment strategy for the management of chronic Pseudomonas aeruginosa infection in cystic fibrosis. Clin Med Insights. 2013;13(7):61-77.

140. Somayaji R, Parkins MD. Tobramycin inhalation powder: an efficient and efficacious therapy for the treatment of Pseudomonas aeruginosa infection in cystic fibrosis. Ther Del. 2015;6(2):121-37.

141. Yayan J, Ghebremedhin B, Rasche K. Antibiotic resistance of Pseudomonas aeruginosa in pneumonia at a single University Hospital Center in Germany over a 10-year period. PLoS ONE. 2015;10(10):e0139836.

142. Hewer SC, Smyth AR. Antibiotic strategies for eradicating Pseudomonas aeruginosa in people with cystic fibrosis. Cochrane Database Syst Rev. 2017:4:004197.

143. Park J, An K, Hwang Y, Park JG, Noh HJ, Kim JY, Park JH, Hwang NM, Hyeon T. Ultra-large-scale syntheses of monodisperse nanocrystals. Nat Mater. 2004;3(12):891-5.

144. Bronstein LM, Huang $X$, Retrum J, Schmucker A, Pink M, Stein BD, Dragnea $B$. Influence of iron oleate complex structure on iron oxide nanoparticle formation. Chem Mater. 2007;19(15):3624-32.

145. Palchoudhury S, An W, Xu YL, Qin Y, Zhang ZT, Chopra N, Holler RA, Turner CH, Bao YP. Synthesis and growth mechanism of iron oxide nanowhiskers. Nano Lett. 2011;11(3):1141-6.

146. Armijo LM, Brandt YI, Mathew D, Yadav S, Maestas S, Rivera AC, Cook NC, Withers NJ, Smolyakov GA, Adolphi NL, Monson TC, Huber DL, Smyth HDC, Osiński M. Iron oxide nanocrystals for magnetic hyperthermia applications. Nanomaterials. 2012;2(2):134-46.

147. Sun Y-P, Li X-Q, Cao JS, Zhang W-X, Wang HP. Characterization of zerovalent iron nanoparticles. Adv Coll Interface Sci. 2006;120(1-3):47-56.

148. Sun Y-P, Li X-Q, Zhang W-X, Wang HP. A method for the preparation of stable dispersion of zero-valent iron nanoparticles. Colloids Surf A. 2007;308(1-3):60-6.

149. Moon B-H, Park Y-B, Park K-H. Fenton oxidation of Orange II by pre-reduction using nanoscale zero-valent iron. Desalination. 2011;268(1-3):249-52.

150. Hwang $Y-H$, Kim D-G, Shin H-S. Effects of synthesis conditions on the characteristics and reactivity of nano scale zero valent iron. Appl Catal B. 2011;105(1-2):144-50.

151. Zhang C, Zhou L, Yang J, Yu X, Jiang Y, Zhou M. Nanoscale zero-valent iron/AC as heterogeneous Fenton catalysts in three-dimensional electrode system. Environ Sci Pollut Res. 2014;21(14):8398-405.

152. Henderson LJ. Concerning the relationship between the strength of acids and their capacity to preserve neutrality. Am J Physiol. 1908:21(2):173-9.

153. Henderson LJ. The theory of neutrality regulation in the animal organism. Am J Physiol. 1908;21(4):427-48.

154. Brown WH, Foote S, Iverson BL, Anslyn EV. Organic Chemistry. 6th ed. Brooks/Cole: Cengage Learning; 2012.

155. Kanicky JR, Shah DO. Effect of degree, type, and position of unsaturation on the pka of long-chain fatty acids. J Colloid Interface Sci. 2002;256(1):201-7.

156. Lee SY, Kim S, Tyler JY, Park K, Cheng JX. Blood-stable, tumor-adaptive disulfide bonded m-PEG-(Cys)-4-PDLLA micelles for chemotherapy. Biomaterials. 2013:34(2):552-61.

157. Liu L, Sun L, Wu Q, Guo W, Li L, Chen Y, Li Y, Gong C, Qian Z, Wei Y. Curcumin loaded polymeric micelles inhibit breast tumor growth and spontaneous pulmonary metastasis. Int J Pharm. 2013;443(1):175-82.

158. Yu Y, He Y, Xu B, He Z, Zhang Y, Chen Y, Yang Y, Xie Y, Zheng Y, He G, He J. Self-assembled methoxy poly (ethylene glycol)-cholesterol micelles for hydrophobic drug delivery. J Pharm Sci. 2013;102(3):1054-62.

159. Seo HW, Kwon DY, Kwon JS, Jin LM, Lee B, Kim JH, Min BH, Kim MS Injectable intratumoral hydrogel as 5-fluorouracil drug depot. Biomaterials. 2013;34(11):2748-57.

160. Wu SC, Lin KL, Wang TP, Tzou SC, Singh G, Chen MH, Cheng TL, Chen CY, Liu GC, Lee TW, Hu SH. Imaging specificity of MR-optical imaging agents following the masking of surface charge by poly(ethylene glycol). Biomaterials. 2013;34(16):4118-27.
161. Li K, Wen S, Larson AC, Shen M, Zhang Z, Chen Q, Shi X, Zhang G. Multifunctional dendrimer-based nanoparticles for in vivo MR/CT dual-modal molecular imaging of breast cancer. Int J Nanomed. 2013;19(8):2589-600.

162. Girard YK, Wang CY, Ravi S, Howell MC, Mallela J, Alibrahim M, Green R, Hellermann G, Mohapatra SS, Mohapatra S. A 3D fibrous scaffold inducing tumoroids: a platform for anticancer drug development. PLOS ONE. 2013;8(10):e75345.

163. Illés E, Tombácz E, Szekeres M, Tóth IY, Szabó Á, Iván B. Novel carboxylated PEG-coating on magnetite nanoparticles designed for biomedical applications. J Magn Magn Mater. 2015;15(380):132-9.

164. Shtykova EV, Huang X, Remmes N, Baxter D, Stein B, Dragnea B, Svergun DI, Bronstein LM. Structure and properties of iron oxide nanoparticles encapsulated by phospholipids with poly (ethylene glycol) tails. The Journal of Physical Chemistry C. 2007;111(49):18078-86.

165. Hermanson GT. Bioconjugate techniques. 3rd ed. London: Academic Press; 2013.

166. Kirby BJ. Micro- and nanoscale fluid mechanics: transport in microfluidic devices. Cambridge: Cambridge University Press; 2010.

167. Clogston JD, Patri AK. Zeta potential measurement. In: McNeil SE, editor Characterization of nanoparticles intended for drug delivery Methods in Molecular Biology. New York: Humana Press; 2011. p. 63-70.

168. Greenwood R, Kendall K. Selection of suitable dispersants for aqueous suspensions of zirconia and titania powders using acoustophoresis. J Eur Ceram Soc. 1999;19(4):479-88.

169. Hanaor D, Michelazzi M, Leonelli C, Sorrell CC. The effects of carboxylic acids on the aqueous dispersion and electrophoretic deposition of $\mathrm{ZrO}_{2}$.J Eur Ceram Soc. 2012;32(1):235-44.

170. Liao SH, Liu CH, Bastakoti BP, Suzuki N, Chang Y, Yamauchi Y, Lin FH, Wu KC. Functionalized magnetic iron oxide/alginate core-shell nanoparticles for targeting hyperthermia. Int J Nanomed. 2015;10:3315-28.

171. Kim DJ, Chung SG, Lee SH, Choi JW. Relation of microbial biomass to counting units for Pseudomonas aeruginosa. Afr J Microbiol Res. 2012;6(21):4620-2.

172. Sauer K, Camper AK, Ehrlich GD, Costerton JW, Davies DG. Pseudomonas aeruginosa displays multiple phenotypes during development as a biofilm. J Bacteriol. 2002;184(4):1140-54.

173. Benamara H, Rihouey C, Abbes I, Ben Mlouka MA, Hardouin J, Jouenne T, Alexandre S. Characterization of membrane lipidome changes in Pseudomonas aeruginosa during biofilm growth on glass wool. PLoS ONE. 2014;9(9):e108478.

174. Klausen M, Heydorn A, Ragas P, Lambertsen L, Aaes-Jørgensen A, Molin S, Tolker-Nielsen T. Biofilm formation by Pseudomonas aeruginosa wild type, flagella and type IV pili mutants. Mol Microbiol. 2003;48(6):1511-24.

175. Hays EE, Wells IC, Katzman PA, Cain CK, Jacobs FA, Thayer SA, Doisy EA, Gaby WL, Roberts EC, Muir RD, Carroll CJ. Antibiotic Substances produced by Pseudomonas aeruginosa. Biol Chem. 1945;159(3):725-50.

176. Speert DP, Farmer SW, Campbell ME, Musser JM, Selander RK, Kuo S. Conversion of Pseudomonas aeruginosa to the phenotype characteristic of strains from patients with cystic fibrosis. J Clin Microbiol. 1990;28(2):188-94.

177. Moritz M, Geszke-Moritz M. The newest achievements in synthesis, immobilization and practical applications of antibacterial nanoparticles. Chem Eng J. 2013;228:596-613.

178. CLSI. Clinical and Laboratory Standards Institute. Performance Standards for Antimicrobial Susceptibility Testing; Twenty-Ninth Informational Supplement. (Wayne, PA) 2019 CLSI Document M100-S24.

179. Simon HJ, Yin EJ. Microbioassay of antimicrobial agents. Appl Microbiol. 1970;19(4):573-9.

180. Sabath LD. The assay of antimicrobial compounds. Hum Pathol. 1976;7(3):287-95

181. Nickel JC, Ruseska I, Wright JB, Costerton JW. Tobramycin resistance of Pseudomonas aeruginosa cells growing as a biofilm on urinary catheter material. Antimicrob Agents Chemother. 1985;27(4):619-24.

182. Hsueh Y-H, Tsai P-H, Lin K-S, Ke W-J, Chiang C-L. Antimicrobial effects of zero-valent iron nanoparticles on gram-positive Bacillus strains and gram-negative Escherichia coli strains. J Nanobiotechnol. 2017;3(15):77.

183. Walters MC, Roe F, Bugnicourt A, Franklin MJ, Stewart PS. Contributions of antibiotic penetration, oxygen limitation, and low metabolic activity 
to tolerance of Pseudomonas aeruginosa biofilms to ciprofloxacin and tobramycin. Antimicrob Agents Chemother. 2003;47(1):317-23.

184. Reller LB, Schoenknecht FD, Kenny MA, Sherris JC. Antibiotic susceptibility testing of Pseudomonas aeruginosa: selection of a control strain and criteria for magnesium and calcium content in media. J Infect Dis. 1974;130(5):454-63.

185. Musk DJ, Banko DA, Hergenrother PJ. Iron salts perturb biofilm formation and disrupt existing biofilms of Pseudomonas aeruginosa. Chem Biol. 2005;12(7):789-96.

186. Diao M, Yao M. Use of zero-valent iron nanoparticles in inactivating microbes. Water Res. 2009;43(20):5243-51.

187. Prince A. Antibiotic resistance of Pseudomonas species. J Pediatr. 1986;108(5):830-4.

188. Tenover FC. Mechanisms of antimicrobial resistance in bacteria. Am J Med. 2006;119(6):S3-10.

189. Vila J, Martí S, Sánchez-Céspedes J. Porins, Efflux pumps and multidrug resistance in Acinetobacter baumannii. J Antimicrob Chemother. 2007;59(6):1210-5.

190. Nikaido HI, Hancock RE. Outer membrane permeability of Pseudomonas aeruginosa. Bacteria. 2012;10:145-93.

191. Rudramurthy GR, Swamy MK, Sinniah UR, Ghasemzadeh A. Nanoparticles: alternatives against drug-resistant pathogenic microbes. Molecules. 2016;21(7):836.
192. Lee C, Kim JY, Lee WI, Nelson KL, Yoon J, Sedlak DL. Bactericidal effect of zero-valent iron nanoparticles on Escherichia coli. Environ Sci Technol. 2008;42(13):4927-33.

193. Chen J, Xiu Z, Lowry GV, Alvarez PJ. Effect of natural organic matter on toxicity and reactivity of nano-scale zero-valent iron. Water Res. 2011:45(5):1995-2001.

194. Kirschling TL, Gregory KB, Minkley EG Jr, Lowry GV, Tilton RD. Impact of nanoscale zero valent iron on geochemistry and microbial populations in trichloroethylene contaminated aquifer materials. Environ Sci Technol. 2010;44(9):3474-80.

195. Bertini I, Gray HB, Lippard SJ, Valentine JS. Bioinorganic chemistry. Mill Valley: University Science Books; 1994.

196. Henle ES, Linn S. Formation, prevention, and repair of DNA damage by iron/hydrogen peroxide. J Biol Chem. 1997;272(31):19095-8.

\section{Publisher's Note}

Springer Nature remains neutral with regard to jurisdictional claims in published maps and institutional affiliations.
Ready to submit your research? Choose BMC and benefit from:

- fast, convenient online submission

- thorough peer review by experienced researchers in your field

- rapid publication on acceptance

- support for research data, including large and complex data types

- gold Open Access which fosters wider collaboration and increased citations

- maximum visibility for your research: over $100 \mathrm{M}$ website views per year

At BMC, research is always in progress.

Learn more biomedcentral.com/submissions 